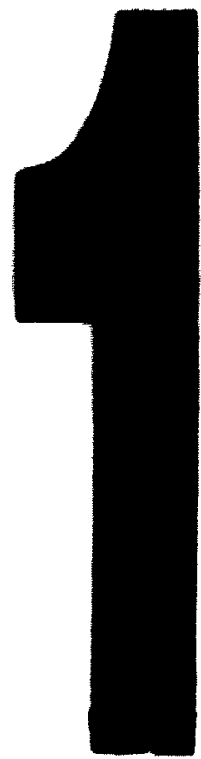

PM-1 3',"4 PHOTOGAAPHIC MICAOCOPY TARGET NBS 10102 ANSI/ISO *2 EOUIVALENT

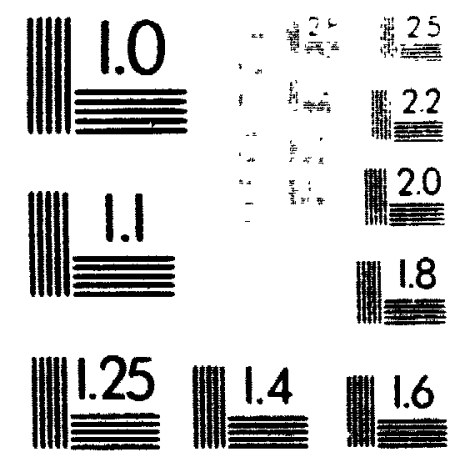

PAECISIONEm RESOLUTION TARCETS 


\title{
ASSESSMENT OF DIRECT SUPERCRITICAL FLUID EXTRACTION OF POLLUTANTS FROM WATER
}

by Rocio Aranda Rodriguez

A thesis submitted to the Faculty of Graduate Studies and Research in partial fulfillment of the requirements for the degree of

Master of Science

Department of Chemistry

\author{
Carleton University \\ Ottawa, Ontario
}

July, 1996 
Natonal Lituary

of rafiara

Arculstums into

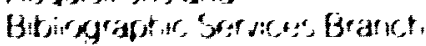

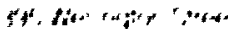

totisin:

- $A: A+A$
Bibliotheque nationate

du Cariada

Direction des acquistions ef

des services bitiographiques

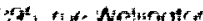

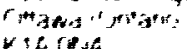

The author has granted an irrevocable non-exclusive licence allowing the National Library of Canada to reproduce, loan, distribute or sell copies of his/her thesis by any means and in any form or format, making this thesis available to interested persons.

The author retains ownership of the copyright in his/her thesis. Neither the thesis nor substantial extracts from it may be printed or otherwise reproduced without his/her permission.
L'auteur a accordé une licence irrévocable et non exclusive permettant à la Bibliothèque nationale du Canada de reproduire, prêter, distribuer ou vendre des copies de sa thèse de quelque manière et sous quelque forme que ce soit pour mettre des exemplaires de cette thèse à la disposition des personnes intéressées.

L'auteur conserve la propriété du droit d'auteur qui protège sa thèse. Ni la thèse ni des extraits substantiels de celle-ci ne doivent être imprimés ou autrement reproduits sans son autorisation.

ISBN $\quad 0-612-19537-6$ 
The undersigned hereby recommend to the Faculty of Graduate Studies and Research acceptance of the thesis

"Assessment of Direct Supercritical Fluid Extraction of Pollutants from Water" submitted by Rocio Aranda Rodriguez, B.Sc., in partial fulfilment of the requirements for the degree of Master of Science

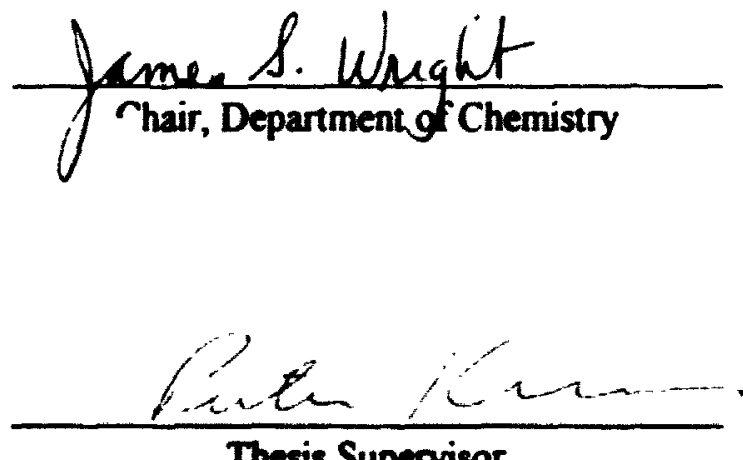

Thesis Supervisor

Carleton University

30ih July 1996 


\section{ABSTRACT}

The use of supercritical fluid $\mathrm{CO}_{2}$ for the extraction of pentachlorophenol from water samples was investigated. Extractions were performed as a function of flow rate and temperature. The suitability of supercritical flund extraction (SFE) as compared with conventional techniques such as liquid liquid extraction (LLE) and solid phase extraction (SPE) was evaluated as well as the possible interference of fulvic acids (FA) in the extractions.

The SFE method was modified froni previous work to speed up the extraction process. The extract was collected directly in $2 \mathrm{~mL}$ of methanol. As a result, in terms of time, SFE is as fast as SPE (1 hour per extraction).

The results obtained in this work suggest that:

1) Fulvic acid at concentration of $20 \mathrm{mg} / \mathrm{L}$ did not interfere in the extraction efficiency.

2) In terms of precision (9-13\%), detection limits (order of ppb), time of extraction (one hour ) and performance, SFE is as suitable as LLE and SPE. However, PCP recovery was somewhat poorer for SFE (60\% as compared to 86 for LLE).

As very little research has been done in direct SFE from water as compared to the other methods, it may be possible to improve the SFE recovery considerably. 
A mis padres y hermanos con todo respeto y cariño 


\section{ACKNOWLEDGMENTS}

I will begin at the beginning

To Peeter Kruus, my esteemed supervisor, whose guidance and support has fostered in me a belief that in life, all is possible. No problemas! Thanks

To Peeter, Annie and the rest of the Kruus Family It is a long way to Mexico. Your kindness and the invaluable friendship that you have provided me in the last few years has sustained me during the hard times and helped me to grow as a person. Gracias!

To Maria, thanks for understanding and being my friend. I will always remember the fulvic acids!, Kram!

To Arghavan, we have shared as many good times as bad (broken legS), and we have done well for ourselves. Thanks to you and your family for all the great moments!

To Peter G.and Claire - Your words of enccuragement have meant a great deal Keep smiling.

To Bob Burk - Your comments have been invaluable to my work. I am grateful that you took the time to help straighten out the numbers!

To Karl and Robert K-Somehow your supplies always met my demands! Thanks.

To Meredith for sharing the HPLC with me.

To Mohammad Lamari for taking the time in explaining various engineering concepts.

To Amina, John and the rest of the Gang, the laughter, the friendship and our experiences (experiments, supervisors and after-hours) are something never to be forgotten. When I think of us, I will smile.

To Fernando, my Mexican friend in Canada and to Kelsey

Special acknowledgements to the Departamento de Becas al Extranjero (DGAPA), UNAM for the financial support. 


\section{AGRADECIMIENTOS}

Quisiera agradecer a todas las personas en México que confiaron en mi e hicieron posible mi estancia en Canada Gracias a ellas he crecido no solamente academicamente sino como persona.

A Ginny por creer en mi y ser siempre mi mentora Gracias.

A Irene y Betina por la invaluable ayuda y siempre estar presente en mis bomberazos

A todas las personas que nunca me clvidaron y cuyos "chisnets" me hicieron sentir que aun estaba en casa.

Al Instituto de Geografia y al Dirección General de Asuntos del Personal Académico (DGAPA), UNAM por todo el apoyo financiero, aún en el momerito tan dificil en el que vive el pais. Gracias. 


\section{TABLE OF CONTENTS}

Acceptance Sheet

Abstract

Acknowledgements

Table of contents

List of tables

List of figures

List of abbreviations

CHAPTER 1: INTRODUCTION 2

1.1 General background 2

1.2 Humic substances

1.3 Water Analysis 8

1.3.1 Sample preparation 9

1.3.2 Liquid-liquid extraction (LLE) $\quad 10$

1.3.3 Solid phase extraction (SPE) II

1.4 Purposes of the study $\quad 12$

CHAPTER 2: SUPERCRITICAL FLUID EXTRACTION (SFE) IS

2.1 Theory 15

2.11 Fluid characteristics 16

$\begin{array}{ll}\text { 2.1.2 Partition coefficient } & 18\end{array}$

$2.1 .3 \mathrm{CO}_{2}$-Water system 23

2.2 Literature review 26

2.2.1 Partition coefficients $\quad 26$

2.2.2 Direct supercritical fluid extractions $\quad 30$

2.2.2.1 Extraction vessel $\quad 30$

22.2.2 Restrictors $\quad 40$

2.2.2.3 Trapping System 41 
CHAPTER 3: EXPERIMENTAL

31 Experimental Design 43

32 Sample Preparation 44

321 Pentachlorophenol stock solution.

32.2 Fulvic acid stock solution 44

$323 \mathrm{PCP}$ in deionized water (PCP/W)

3.2.4 PCP in fulvic acid solution (PCP/FA)

3.2.5 Real sample $\quad 45$

32.6 PCP calibration standards $\quad 46$

33 Supercritical fluid extractions (SFE) 46

331 SFE using a solid phase trap 46

332 Supercritical Fluid Extraction with the fused silica capillary restrictor 49

3 3.3 Supercritical Fluid extraction at different temperatures 51

3.4 Extractions of PCP/W and PCP/FA

3.4.1 Liquid-liquid extraction (LLE) 51

34.2 Solid phase extraction (SPE) 52

3.4.3 Supercritical fluid extraction 53

3.5 Extraction of PCP from real samples 53

3.6 Analysis 53

3.7 Data Analysis 55

CHAPTER 4: RESULTS AND DISCUSSION 57

4.1 HPLC Analysis 57

4.2 Supercritical Fluid Extraction: feasibility studies $\quad 57$

4.2.1 SFE using a solid phase trap $\quad 57$

4.2.2 SFE using a fused silica capillary as restrictor 61

4.3 Effect of temperature on SFE

44 Effect of fulvic acid on the extractions 65

4.4.1 Liquid Liquid Extraction (LLE) 66

4.4.2 Solid Phase Extraction (SPE) 66

4.4.3 Supercritical luid extraction (SFE) 68

4.5 Pentachlorophenol extractions from Ottawa river water 73 
CHAPTER 5: CONCLUSIONS

70

5.1 Feasibility studies $\quad 76$

511 Apparatus

5.1.2 Extraction

76

76

52 Effect of fulvic acid in the extraction of PCP by LLE, SPE and SFE

77

5.3 Application of SFE to real samples

CHAPTER 6: REFERENCES

80

Appendix 1: Pentachlorophenol chromatograms 84

Appendix 2: PCP calibration curve 85

Appendix 3: $\mathrm{PCP}$ recovery as function of volume of $\mathrm{SFCO}_{2} \quad 86$

Appendix 4: Statistical analysis $\quad 88$

Appendix 5: Pressure conversion table $\quad 92$ 


\section{LIST OF TABLES}

Table 1.1 1994 Water quality results of the regional municipality of OttawaCarleton Ottawa river and Lemieux Island/Britannia water purification plants (1994 water quality report).

Table 1.2 Results of trace organics, Distribution system (1994 water quality report)

Table 1.3 Comparison of extraction technique for organic compounds (Koester et al., 1993).

Table 2.1 Predicted species concentration for $\mathrm{CO}_{2}, \mathrm{H}_{2} \mathrm{O}$ at $323 \mathrm{~K}$ and various pressures (from Wang et al, 1996).

Table 2.2 Summary of partition coefficients from different references.

Table 4.1 PCP recoveries by two different restrictors and traps.

Table 4.2 Extractions efficiencies at $40^{\circ} \mathrm{C}$ with the fused silica capillary and 40 $\mathrm{mL}$ of $\mathrm{SFCO}_{2}$ passed through the sample.

Table 4.3 PCP recovery with three different methods; the samples were extracted on the 10th day after their preparation $([P C P]=0.200 \mathrm{mg} / \mathrm{L})$.

Table 4.4 PCP recovery with three different methods: LLE, SPE and SFE. Volume of sample: $20 \mathrm{~mL}$ and concentration of PCP $200 \mathrm{ppb}$.

Table 5.1 Comparison of extraction methods for PCP.

Table III.1 PCP recovery as function of volume of SFCO2 passed through the sample (cumulative). The samples were extracted one day after sample preparation.

Table II.2 PCP recovery as function of SF volume (cumulative). The samples were extracted ten days after sample preparation.

Table IV.1 PCP recovery as function of flow rate. Extractions performed at 3000 psi and $40^{\circ} \mathrm{C}$.

Table IV.2 Analysis of variance at 0.05 level of significance.

Table IV.3 Comparison between extraction methods (LI.E, SPE and SFE) for PCP in deionized water and PCP in a solution containing $20 \mathrm{ppm}$ of FA.

Table IV.\& ANOVA, differences between extraction method and sample type. 


\section{LIST OF FIGURES}

Figure 1.1. Structure of humic substances (Stevenson, 1994)

Figure 1.2 Water analysis fl $\cdots$ (from Cram et al . 1996)

Figure 2.1 Variation of the reduced density of a pure component in the vicinity of its critical point (from Burk, 1990). See Appendix 5 for pressure conversion.

Figure 2.2 Solubility of water in supercritical $\mathrm{CO}_{2}$ as a function of pressure

Figure 2.3 Mutual solubilities of water with supercritical and liquid $\mathrm{CO}_{2}$. a)solubility of water in liquid and $\mathrm{SFCO}_{2}$ b) solubility of $\mathrm{CO}_{2}$ in water (data from King et al., 1992)

Figure 2.4 Experimental values of $K$ for phenol at different temperatures and pressures.

Figure 2.5 Supercritical fluid-liquid equilibrium apparatus (from Ghonasgi et al . 1991).

Figure 2.6 Extraction vessel for SFE from aqueous samples (a) Hedrick et al . 1992 and (b) Barnabas et al., 1994

Figure 2.7 Representation of liquid-fluid extraction at low and high $\mathrm{CU}_{2}$ density 34

Figure 2.8 Extraction vessel and drubbler (From Brewer et al., 1993)

Figure 2.9 Schematic flow diagram of semicontinuous supercritical fluid extraction system (from Chang et al., 1995).

Figure 3.1 a) Supercritical fluid extraction apparatus, b) solid phase trap (Brewer, 1995).

Figure 3.2 Restrictors: a) fused silica capillary (Burk, 1990), b) as used in this study

Figure 4.1 PCP recovery, extraction condition: $3000 \mathrm{psi}, 40^{\circ} \mathrm{C}, \mathrm{SFCO}_{2}$ density $0.85 \mathrm{~g} / \mathrm{mL}, 20 \mathrm{~mL} \mathrm{SFCO}$

Figure 4.2 Extractions prefiles of pentachlorophenol at $21^{\circ} \mathrm{C}$ a) without fulvic acid and b) with fulvic acid. Minimum of three experiments per point.

Figure 4.3 PCP recoveries obtained by different methods in absence and presence of fulvic acids. 


\title{
LIST OF ABBREVIATIONS
}

\author{
ANOVA Andysis of variance \\ DCM Dichloromethane \\ DOM Dissolved organic matter \\ EOS Equation of state \\ FA Fulvic Acids \\ GC/ECD Gas chromatography with electron capture detector \\ HPLC High pressure liquid chromatography \\ HS Humic substances \\ $K \quad$ Partition coefficient \\ LLE Liquid liquid extraction \\ MTBE Methyl-t-butylether \\ P Pressure \\ PCP Pentachlorophenol \\ ppb Parts per billion ( $\mu \mathrm{g} / \mathrm{L})$ \\ ppm Parts per million (mg/L) \\ ppt Parts per trillion ( $\mathrm{ng} / \mathrm{L}$ ) \\ P \& $T$ Purge and Trap \\ RSD Relative standard deviation \\ SF Supercritical Fluid \\ SFC Supercritical fluid chromatography \\ SFE Supercritical Fluid Extraction \\ SPE Solid phase extraction \\ TC Total carbon \\ TIC Total inorganic carbon \\ TOC Total organic carbon \\ VOC Volatile organic compounds
}




\section{Chapter 1}

"No one science sees more than details of the real world. How to develop a shared conception of reality is a research issue in itself FALKENMARK 


\section{INTRODUCTION}

This document is organized to first introduce to the reader the importance of water analysis as a tool for monitoring its quality. In the second part of chapter 1, a brief description of humic substances will be presented as it has been known for decades that humic substances play an important role in the fate of metals and organic compounds. Only recently have a number of researchers noticed their influence in water analysis. Sample preparation in such analysis will be discussed to introduce the techniques used in this study.

In chapter 2, the relevant theory on supercritical fluids will be discussed followed by a review of the recent literature.

\subsection{General background}

Potable water availability is an important issue throughout the world. This has emerged as a result of global population growth and contamination of water reservoirs. About 1.2 billion people lack clean and safe water and suffer from diseases associated with insufficient or contaminated water.

As a result, water quality has emerged as a primary problem. Not only is drinking water supply important, but also the water for agricultural and industrial needs. Drinking water is obtained from surface water or ground water. Even though water is usually pretreated before reaching the population, it is important to have a water quality regulation for all water sources. There are thus regulations for water quality, such as the 
Canadian Water Quality Galidelines (CWQG, 1978), and the Safe Drinking Water Act in the United States.

Most water pollution problems affect developing countries. Pollution by pesticides has increased with their use for disease-control programs (e.g. malaria) and agricultural production. Developed countries, on the other hand, have restricted the use of many organic compounds such as DDT, aldrin and heptachlor. However, they may be found in the environment due to their long lifetime and migration properties. Some other organic compounds may enter the aquatic environment while being manufactured and applied. Their ultimate fate depends on their physico-chemical properties and the surroundings. In order to evaluate water quality, analysis of water for such pollutants is of paramount importance.

\subsection{Humic substances}

Natural uaters contain a diversity of dissolved and particulate inorganic and organic constituents. Lakes and rivers have approximately 10 times more dissolved inorganic matter than organic matter, whereas groundwater has 100 times more inorganic matter than organic mater (CWQG, 1987).

Organic carbon is composed of both dissolved and particulate form. Total organic carbon (TOC) is often calculated as the difference between total carbon (TC) and total inorganic carbon (TIC). In water, organic carbon is principally composed of humic substances. 
Dissolved and particulate matter are operationall! separated with the use of 0.45 $\mu \mathrm{m}$ pre-size filter. Material passing through is considered dissolved, and the remainder particulate. Both of these classes of matter consist of organic (e.g. proteins, fats, carbohydrates and related compounds) and inorganic material (e.g. suspended minerals, rock particles, clays, salts).

Humic substances (HS) represent a significant fraction of the bulk of organic matter in most soils and water. HS contain molecules with large molecular weights (3,000-30,000 daltons). They contain functional groups such as hydroxyl, phenolic and carboxyl groups confering to the HS a hydrophilic and acidic character. On the other hand, the large carbon chains and the ability to form intrachain hydrogen bonds confer to the HS molecule a globular structure and some hydrophobic character (Figure 1.1). Because of their polyelectrolytic nature, HS have the ability to bind to various inorganic and organic compounds.

HS may be classified into three fractions based on their solubility, which is $\mathrm{pH}$ dependent. Structurally they are believed to be similar; however, they differ in molecular weight and functional group content. The three fractions are:

- humic acids, which are soluble in alkaline solutions but precipitate in acidic solutions;

- fulvic acids, which are soluble over the entire pH range due to their lower molecular weight and higher acidity;

- humin, the fraction that is insoluble at all pH levels. 

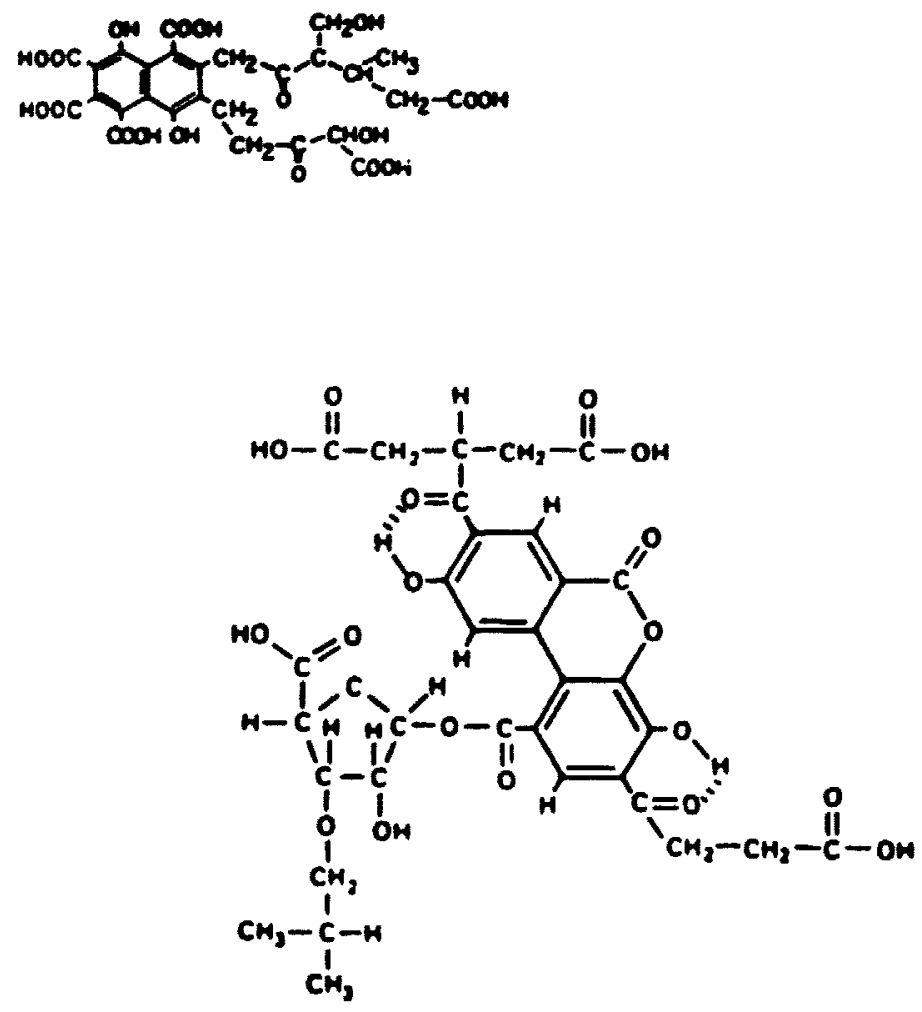

Figure 1.1. Structure of humic substances (Stevenson, 1994). 
Only recently has the importance of dissolved organic matter been recognized.

The distribution of organic compounds in water is governed, in part, by the extent of the interaction between them and the HS.

It has been reported that HS (the major part of dissolved organic matter [DOM]) enhance the apparent solubility of non polar compounds (from Suffet et al., 1989); modifying their bioavailability and toxicity. Wershaw et al. (from Suffet et al., 1989) found that the apparent water solubility of DDT increased more that 200 times in an aqueous solution containing HS. Maguire et al. (1995) reported that DOM can affect the recoveries of organic compounds by liquid-liquid extraction (LLE) and solid phase extraction (SPE).

HS can also exert a competitive effect on the adsorption of volatile organic compounds on activated carbon during treatment of drinking water, and adversely affect the efficie'scy of oxidative water treatment processes.

Trihaloalkanes have been identified in the concentrated extracts of chlorinated natural waters, and humic substances in water are considered to be their precursors (Hayes et al., 1989). Concentration of trihalomethanes in raw water from the Ottawa river was less than $5 \mathrm{ppb}$. The amount found after treatment was from 12 to $80 \mathrm{ppb}$ (taivie 1.1)(1994 Water quality report). 
Table 1.11994 Water quality results of the regional municipality of Ottowa-Carleton Ottowa river and Lemieux Island Brttamia water purification plams (1994 water quality report).

\begin{tabular}{|c|c|c|c|c|c|c|c|}
\hline \multirow[t]{3}{*}{ Parameter } & \multicolumn{3}{|c|}{ Raw water } & \multicolumn{3}{|c|}{ Treated water } & \multirow{3}{*}{$\frac{\text { M.A.C }}{\mathrm{mg} / \mathrm{L}}$} \\
\hline & \multicolumn{3}{|c|}{$\mathrm{mg} / \mathrm{L}$} & \multicolumn{3}{|c|}{$\mathrm{mg} / \mathrm{L}$} & \\
\hline & $\min$. & $\max$ & avg & $\min$ & $\max$ & avg & \\
\hline Suspended solids & 17 & 90 & 51 & - & - & - & NL \\
\hline Dissolved solids & 33.7 & 68.7 & 37.2 & $=$ & - & - & $500(\mathrm{AO})$ \\
\hline Total solids & 42.7 & 69.0 & 544 & 40.0 & 92.0 & 72.8 & $\mathrm{NL}$ \\
\hline Diseolved oreanic Cerbon & 6.1 & 6.6 & 6.4 & 2.7 & 3.5 & 3.0 & $5.0(\mathrm{AO})$ \\
\hline Trihalomethanes & $<0.005$ & $<0.005$ & $<0005$ & 0.012 & 0.08 & 0.034 & $0.350(1)$ \\
\hline Phenols & 0.0002 & 0.0014 & $\begin{array}{l}0.0006 \\
0\end{array}$ & $\begin{array}{l}0.0004 \\
0\end{array}$ & 0.0010 & $\begin{array}{l}0.0007 \\
0\end{array}$ & NL \\
\hline & & & & & & & \\
\hline
\end{tabular}

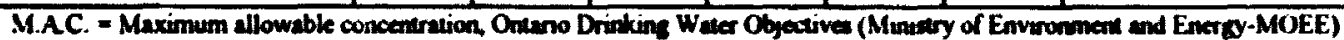

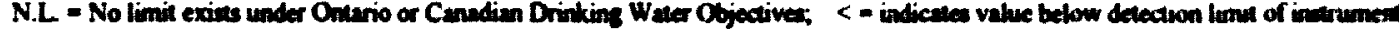

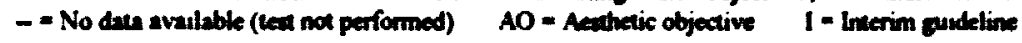

Table 1.2 Results of trace organics, Distibution system (1994 water quality report).

\begin{tabular}{|c|c|c|c|}
\hline Compund detected & $\begin{array}{l}\text { of positive } \\
\text { results/ } \\
\text { of Sampes } \\
\text { tested }\end{array}$ & $\begin{array}{l}\text { Concentration } \\
\text { Range ( } \mu \mathrm{g} / \mathrm{L} \text { or } \\
\mathrm{ppb)}\end{array}$ & $\begin{array}{l}\text { Average concentration } \\
\text { of positive results } \\
(\mu \mathrm{g} / \mathrm{L} \text { or } \mathrm{ppb})\end{array}$ \\
\hline Chloroform & $15 / 15$ & $5-49.7$ & 26.5 \\
\hline Bromoform & $1 / 15$ & 0.6 & $0.6^{*}$ \\
\hline Bromodichloromethane & $11 / 15$ & $0.8-5.6$ & 2.3 \\
\hline Dibromochloromethane & $1 / 15$ & 42 & 42 \\
\hline Ethylbenzene & $1 / 6$ & 0.10 & $0.10^{*}$ \\
\hline Hexachloroethane & $2 / 6$ & 0.003 & $0.003^{*}$ \\
\hline Toluene & $1 / 6$ & 0.10 & $0.10^{*}$ \\
\hline Styreme & $3 / 6$ & $0.05-0.15$ & $0.83^{\circ}$ \\
\hline 2,4,6-Trichlorophenol & $1 / 6$ & 0.05 & $0.05^{\circ}$ \\
\hline M-Xylene & $1 / 6$ & 0.10 & $0.10^{*}$ \\
\hline
\end{tabular}

\footnotetext{
- Trice Quantity: Interpre with caution
} 


\subsection{Water Analysis}

Water analysis consist of several steps (Figure 1.2).

\section{Sample Analysis Flow Diagram}
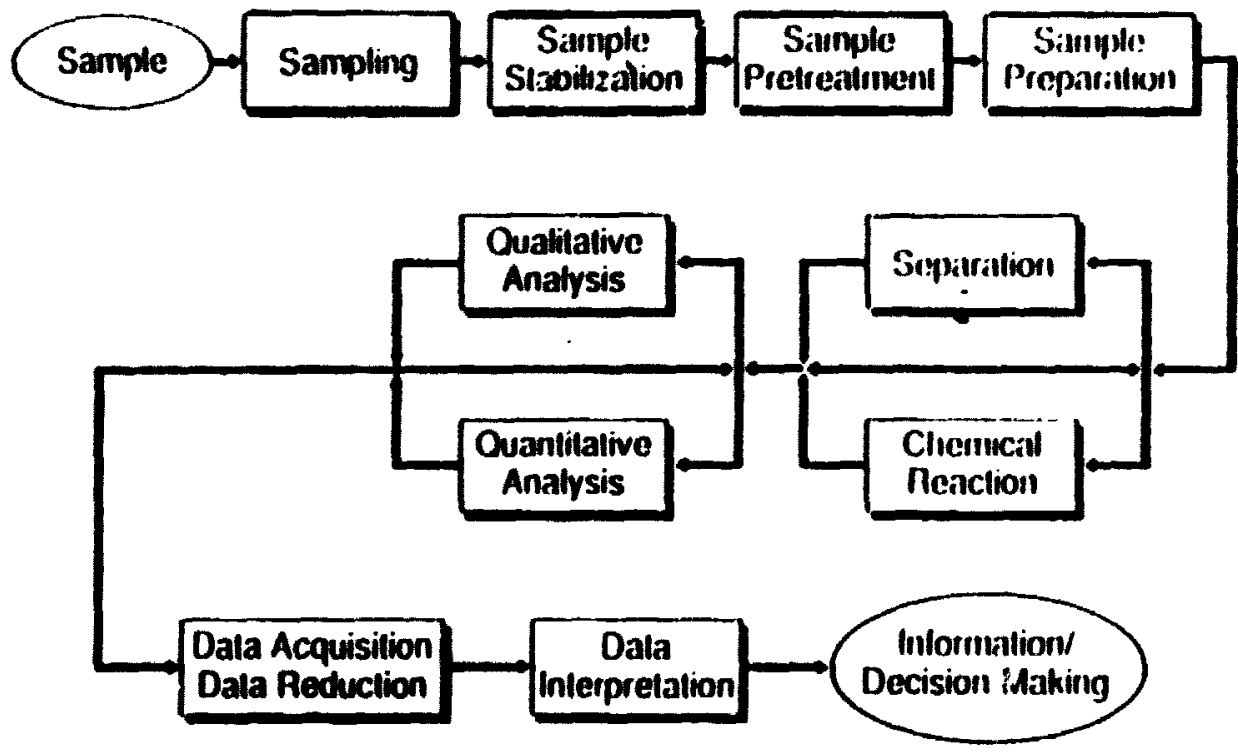

Figure 1.2. Water analysis flow (from Cram et al., 1996). 
Sample collection must fulfill the objective of the analysis, some factors that must be considered are: sampling location, time of sampling and frequency of the sampling among others

Sample stabilization is meant to retard bacterial growth and to prevent acid or base catalyzed decomposition. The most common way of doing this is through pH adjustment or the use of additives such as sodium thiosulfate and mercuric chloride

\subsubsection{Sample preparation}

The objective of sample preparation is to extract the analyte from the sample matrix into a phase compatible with the separation method. Some of the benefits obtained are: minimization of the matrix effects, preconcentration of the analyte, and reduction of the interferences.

In sample preparation, some of the problems that can be encountered are:

1) time; it has been reported that two-thirds of analysis time is spent on sample preparation.

2) sample recovery; poor recoveries will lead to underquantitation of the analyte and misinterpretations of the results.

3) contamination, which affects the precision; it can be diminished by the use of high purity solvents.

4) cost of analysis, which is partly due to the use of high purity solvents and laboratory waste production.

5) lack of reproducibility. 
The extraction of analytes from aqueous samples is achieved by three techniques (Koester et al., 1993), based on the physico-chemical properties of the analyte(s):

1) by head space techniques in which the organic compounds are transferred to the gas phase by either a static or a dynamic way. In the dynamic method, the sample is sparged by bubbling it with an inert gas, the most common technique is Purge and Trap (P\&T). This technique is used for volatile organic compounds (VOCs).

2) by liquid-liquid extraction (LLE), in which a water immiscible organic solvent is contacted with the water sample after which the two phases are allowed to separate.

3) by solid phase extraction (SPE) in which the sample is passed through a solid phase (cartridge or disk); the analyte(s) are adsorbed onto the solid. The analytes are then eluted with a solvent.

\subsubsection{Liquid-liquid extraction (LLE)}

Liquid-liquid extraction is the most commonly used technique. It is based on the partition of the analyte between two phases: water and a water immiscible organic phase. The ratio of the concentration of the analyte between the two phases is represented by the partition coefficient as follows:

$$
K=C_{0} C_{w}
$$

Where $C_{o}$ is the concentration of the analyte in the organic phase and $C_{w}$ is the concentration of the analyte in the water. The larger the value of $K$, the more efficient the extraction. 
The solvents commonly used in LLE are hexane, dichloromethane (DCM) and methyl-t-butylether (MTBE). Although DCM is the solvent of choice, its use has been restricted due to its toxicity. If one liter of sample is sequentially extracted w.th three portions of $100 \mathrm{~mL}$ of DCM, I mL goes to the vial for analysis, $16 \mathrm{~mL}$ dissolves in waste water and $283 \mathrm{~mL}$ goes into the atmosphere (Cram et al., 1996).

LLE is widely used because it is easy to perform and to be automated; however. large amounts of high purity solvents are needed. It has been reported that the disposal cost of some solvents can equal the purchase price (Majors, 1995)

From the technical point of view, some problems are due to emulsion formation. Studies reported that waters containing high concentrations of humic materials are prone to form emulsions (Liu et al., 1994).

\subsubsection{Solid phase extraction (SPE)}

Solid-phase extraction is based on the transfer of the analyte from a liquid or gas phase to the solid phase. The analyte is selectively adsorbed onto the surface of the solid phase and then desorbed by the addition of a small amount of organic solvent or by means of supercritical fluid extraction. In SPE, both separation and concentration are obtained. The solid phase is usually a silica-bonded phase similar to those used in liquid chromatography. A common type is the Empore disk. This is made up of particles with a small size $(8 \mu \mathrm{m})$. The result is a surface area of $500 \mathrm{~m}^{2} / \mathrm{g}$, so that the adsorption kinetics are fast, resulting in a fast extraction (Koester et al., 1993). 
There are several advantages in using SPE. it is easy to use and to automate, little solvent is used and no emulsion problems are faced. However, in preconditioning the disk, about $30 \mathrm{~mL}$ of solvent is required. Moreover, this is a problem of disposal of the solid phase. Table 13 shows the comparison between the extraction techniques.

Table 1.3 Comparison of extraction technique for organic compounds (Koester et al., 1993).

\begin{tabular}{|c|c|c|c|c|c|c|c|}
\hline Technique & Applicability & $\begin{array}{l}\text { Denection } \\
\text { lima } \\
\text { (MS) }\end{array}$ & $\begin{array}{l}\text { Precision } \\
\% \text { RSD }\end{array}$ & Expense & Time & $\begin{array}{l}\text { Solvent } \\
\text { use }\end{array}$ & $\begin{array}{l}\text { Easy to } \\
\text { perform }\end{array}$ \\
\hline P\&T & VOC & ppo & $1-30$ & High & $30 \mathrm{~min}$ & none & No \\
\hline CLS & VOC & ppt & $3-20$ & High & $2 h$ & none & No \\
\hline LLE & SVOC & $p p t$ & $5-50$ & High & $1 \mathrm{~h}$ & $200 \mathrm{~mL}$ & Yes \\
\hline SPE & SVOC, polar & $\mathrm{ppt}$ & 7.15 & Medium & $30 \mathrm{~min}$ & $80 \mathrm{~mL}$ & Yes \\
\hline SFE & & ppb & & Medium & $30 \mathrm{~min}$ & $1.5 \mathrm{~mL}$ & No \\
\hline
\end{tabular}

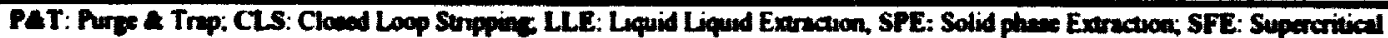

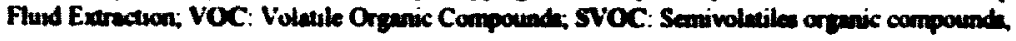

\subsection{Purposes of the study}

Only a small number experiments have been reported on the direct supercritical fluid extraction (SFE) from water samples (Section 2.2.2). The main approach in the use of supercritical fluids (SFs) has been a solid phase extraction followed by SF as the eluting solvent. One purpose of the work was to assess the effectiveness of the direct extraction of organic compounds with supercritical $\mathrm{CO}_{2}$, as sample preparation method for analytical purposes, and compare it to other methods of extraction, specifically LLE and SPE. 
Dissolved organic matter (DOM) (e g humic substances) are ubiquitous in natural water. They can interact with organic compounds and enhance their apparent solubility. especially of non-polar species. The HS can also interfere with extraction, possibly in different ways with different extraction methods Another purpose of this study was to investigate the interferences by HS in the extraction.

Fulvic Acids (FA) were selected to represent the DOM because of their solubility in the whole range of $\mathrm{pH}$. Humic acids are insoluble at a low $\mathrm{pH}$ and water in contact with $\mathrm{SFCO}_{2}$ has a pH of about 2.9 (Toews, 1995).

Pentachlorophenol (PCP) was chosen as a representative compound of the chlorophenoi class. PCP has been used in sawmills, preservation of leather, and as herbicide in pineapple, sugar cane and rice fields (Jorens et al , 1993)

In summary, the more specific purposes of this study were:

- To further develop direct SFE of analytes from water.

- To compare the effectiveness of SFE with the other methods of extraction from liquids, with $\mathrm{PCP}$ as analyte.

- To evaluate the sensitivity of these methods in the presence of fulvic acids.

- To evaluate the effectiveness of SFE when using raw river water spiked with PCP 
Chapter 2 


\section{SUPERCRITICAL FLUID EXTRACTION (SFE)}

Although supercritical fluid extraction (SFE) for organic compounds from diverse matrixes have been reported (Janda et al., 1993), most of the reports have focused on solid samples (soils, adsorbents, activated carbon). Few experiments have been done in the direct extraction of organic compounds from aqueous samples. Direct supercritical fluid extraction from aqueous samples is more complicated than that from solid samples due to some mutual miscibility of water and the supercritical $\mathrm{CO}_{2}$. This causes plugging of the restrictor and problems with GC analysis due to the presence of water in the extract.

\subsection{Theory}

Statements have been repeatedly made in the supercritical fluid literature that supercritical fluids are the solvent of choice due to their liquid-like density, high molecular diffusivities and low viscosity. The aim of this section is to explain the theory behind supercritical fluid extraction (SFE) from aqueous samples.

Because supercritical fluids are something between gas and liquid, SFE can be seen something between liquid-liquid extraction (LLE) and purge \& trap (P\&T) in which the solvent/gas is a supercritical fluid. In some direct SFE, the design of the extraction vessel is such that the system resembles P\&T, in which the sample is sparged with bubbles. Since SF is not exactly a gas, the term "drubbles" (droplets/bubbles) rather than "bubbles" is suggested. 
In LLE, the analyte(s) is transferred from the aqueous phase to the organic phase. The two liquids are essentially immiscible with each other so that the separation of the phases is achieved. In $\mathrm{SFCO}_{2}$-water system there is some mutual miscibility. The auccess of the extraction depends on the relative solvent powers and the mass transfer rates.

\subsubsection{Fluid characteristics}

Basically the solvent strength of a SF is given by its density. A change in density is attained by changing the pressure and/or temperature. Notable changes occur at reduced temperatures $\left(T_{r}=T / T_{c}\right)$ in the range of 0.9-1.2 and reduced pressures $\left(p_{r}=p / p_{c}\right)$ of greater than $I$ in which the solvent densities change from 0.1 to 1.5 (Figure 2.1). Intermolecular interactions between solvent and solute determine how well the solute molecules will be solvated.

Another way of changing the solvent strength is by adding to the SF a second component (also known as cosolvent, entrainer or modifier) which interacts more strongly with the solute than the SF. The most common cosolvent is methanol, but the use of acetone, hexane and water as cosolvents have been reported. 


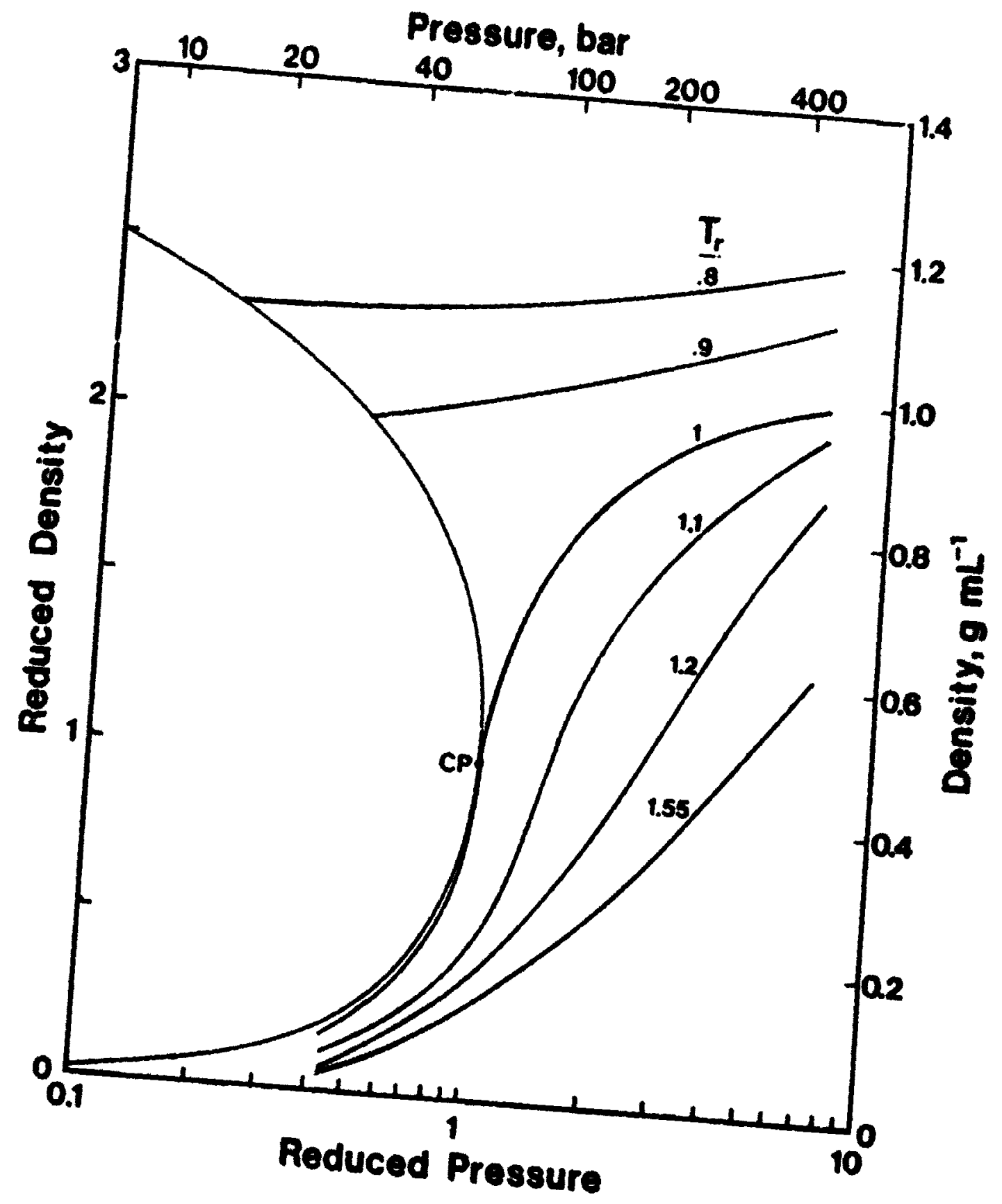

Figure 2.1 Variation of the reduced density of a pure component in the vicinity of its
critical point (from Burk, 1990). See Appendix 5 for pressure unit comversion. 


\subsubsection{Partition coeficient}

When dealing with extraction from water samples, the solubility of a compound in the SF alone fails to predict the success of an extraction, since the analyte will partition between the two phases.

One alternative is the use of fugacities for both phases. The application of fugacity coefficients is possible, but may not result in quantitative predictions. The fugacities in the SF phase and liquid phase are expressed as:

$$
\begin{aligned}
& f_{i}^{\mathbb{F}}=\phi_{i}^{\$ F} y_{i} p \\
& f_{i}^{L}=\phi_{i}^{L} x_{i} p
\end{aligned}
$$

at equilibrium

$$
\begin{aligned}
& f_{1}^{S F}=f_{1}^{L} \\
& \frac{y_{1}}{x_{i}}=\frac{\phi_{1}^{L}}{\phi_{1}^{S}}=K
\end{aligned}
$$

The partition coefficient $(K)$ is the ratio of mole fraction of the analyte in the SF $\left(y_{1}\right)$ and the liquid phase $\left(x_{i}\right)$. Usually the value of $K$ is obtained from experimental data. Equations of state (EOS) such as Peng-Robinson and Redlich-Kwong have been used to model the data and calculate the fugacity coefficients. Mixing rules have been utilized in order to model mixture properties. However, the predictions of partition coefficients by such means has not proven to be very reliable. 
Supercritical $\mathrm{CO}_{2}$ is classified as a non-polar solvent, but its large quadrupole moment leads to some affinity with polar solutes; thus many polar organic molecules are at least partially soluble in it. Supercritical $\mathrm{CO}_{2}$ is thus an excellent solvent for nonpolar compounds, but it fails to quantitatively extract polar compounds and ionic compounds.

For the extraction of polar compounds, polar modifiers such as methanol have been used. However, the use of a modifier is not the only way to enhance the extraction efficiency. By transforming the polar molecules into a less polar form, the extraction efficiency is increased. This can be done by two methods, which will be considered: acid/basic compounds and derivatization.

pH equilibrium in SFE; the extraction of acidbase compounds

At supercritical $\mathrm{CO}_{2}$ conditions, water becomes acidic due to the miscibility of $\mathrm{CO}_{2}$ in water followed by the formation of carbonic acid and its deprotonation. Because of that, the partition coefficient of acid-base compounds can be modified depending on the pH of the aqueous matrix (determined by the extraction conditions, i.e. $T$ and $p$ ).

The solubility of $\mathrm{CO}_{2}$ gas in water is expressed ideally by Henry's law:

$$
p_{1}=y_{1} p=K_{1} x
$$

At a partial pressure of $\mathrm{CO}_{2}$ over the solution of 1 atm the solubility of $\mathrm{CO}_{2}$ in water at $298 \mathrm{~K}$ is $0.037 \mathrm{~mol}$. 
In solution, the following equilibrium takes place:

$$
\begin{array}{rc}
\mathrm{H}_{2} \mathrm{O}_{(l)}+\mathrm{CO}_{2(8)} \leftrightarrow \mathrm{CO}_{2(a q)}+\mathrm{H}_{2} \mathrm{O}_{(l)} \leftrightarrow & \mathrm{H}_{2} \mathrm{CO}_{3(a q)} \\
& I_{K_{1}} \\
& \mathrm{H}_{(a q)}^{+}+\mathrm{HCO}_{3(a q)}^{-} \\
& I_{K_{2}} \\
& 2 \mathrm{H}_{(a q)}^{+}+\mathrm{CO}_{3(a q)}^{2-}
\end{array}
$$

Carbonic acid is a diprotic acid and thus has two pK, values. Under a normal atmosphere, the $\mathrm{pH}$ of water is 5.6 due to the solubility of $\mathrm{CO}_{2}$ in air $(350 \mathrm{ppmV})$ as predicted by Henry's law and the pK, values. Under supercritical conditions, the ideality is however not followed.

King et al. (1992) obtained the mutual solubility of $\mathrm{CO}_{2}$ and water, and applied Henry's Law, Raoult's law and the Redlich-Kwong EOS to obtain the fugacity of the components. The solubility of liquid $\mathrm{CO}_{2}$ in water at $298 \mathrm{~K}$ and $200 \mathrm{~atm}$ is $2.73 \mathrm{~mole} \mathrm{CO}_{2}$ per hundred moles of solution. They did not calculate the $\mathrm{pH}$ of the solution; however,

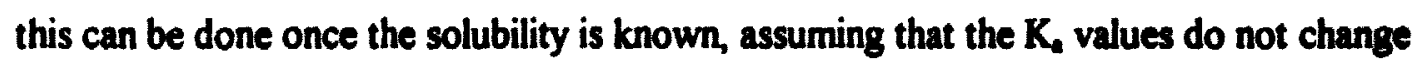
with p.

Wang et al. (1996) estimated the $\mathrm{pH}$ and the $\mathrm{CO}_{2}$ species present in solution as a function of pressure (Table 2.1). The calculations were performed by using a computer program. The last column shows the values of pH obtained by Toews et al. (1995). The data agreed with the fact that at high pressures, the $\mathrm{pH}$ of the solution is lower than 3. 
Table 2.1 Predicted species concentration for $\mathrm{CO}_{2}, \mathrm{H}_{2} \mathrm{O}$ at $323 \mathrm{~K}$ and various prescures (from Wang et al., 1996). See Appendix 5 for pressure unt conversion.

\begin{tabular}{|c|c|c|c|c|c|c|c|}
\hline 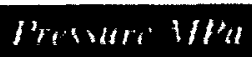 & $p h$ & pll & plltis & for & (1) & 111010.1 & 111 \\
\hline 44.69 & 15.53 & 2.69 & 2.69 & 10.12 & 10.55 & 11.30 & \\
\hline 37.81 & 15.60 & 2.72 & 2.72 & 10.12 & 10.52 & 9.63 & \\
\hline 30.94 & 15.69 & 2.76 & 2.77 & 10.14 & 10.48 & 7.83 & \\
\hline 24.06 & 15.80 & 2.82 & 2.82 & 10.12 & 10.42 & 6.08 & 2.85 \\
\hline 17.19 & 15.95 & 2.90 & 2.90 & 10.12 & 10.34 & 4.30 & 2.85 \\
\hline 10.31 & 16.62 & 3.23 & 3.24 & 10.13 & 10.02 & 0.92 & 2.88 \\
\hline
\end{tabular}

- Data obtained from Toews et al. (1995) at 20.2, 15.1 and 10.1 MPa at $50^{\circ} \mathrm{C}$

Calculation were performed using the dat bece contained in $\mathrm{MNEQL} \mathrm{KKCO}_{2}=-\log \left(\mathrm{K}_{\mathrm{H}} \times \mathrm{K}_{1} \times \mathrm{K}_{2} \times \mathrm{pCO}_{3}\right)$. estimated using Henry's Law constant $=10^{-1.5}, \mathrm{pK}_{2}=10.33, \mathrm{pK}_{1}=6.35$, partial pressure $\mathrm{CO}_{2}$ (atm)

Case I. Acidic compounds.

Consider the extraction process where the analyte to be extracted is a weak acid (PCP written as ROH; or a carboxylic acid as $\mathrm{RCOOH}$ ).

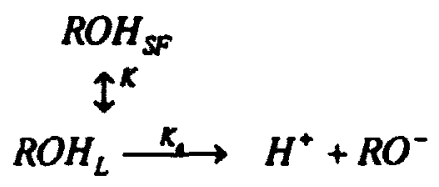

The partition coefficient is determined by the ratio of the mole fraction of the protonated form in the SF and in the liquid phase. Since the protonated form is dependent on the $\mathrm{pH}$ of the solution, consequently the value of $K$ is $\mathrm{pH}$ dependent. In SFE of acidic compounds, this could be an advantage. Several authors have discussed the extraction of phenolic compounds (Table 2.2, page 27). 
Case II. Basic compounds.

Amin:s are the most commonly studied bases; they can accept a proton from water as expressed in the reaction:

$$
\begin{aligned}
& R-\ddot{N} H_{2}+H_{2} \ddot{O} \stackrel{K_{1}}{\longrightarrow} R N^{+} H_{3}+-O H \\
& \text { Where } \\
& K_{b}=\frac{\left.\left[R-N^{+} H_{3}\right]^{-} O H\right]}{\left[R N H_{2}\right]}
\end{aligned}
$$

It is expected that in SFE, the proton donated by the $\mathrm{CO}_{2}$ (through $\mathrm{H}_{2} \mathrm{CO}_{3}$ ) reacts with the amines, giving a salt. Therefore, the amines should be more soluble in water and have low values of $K$. It has been suggested that highly basic amines react with $\mathrm{CO}_{2}$ to form carbamates: $\quad \mathrm{H}_{2} \mathrm{~N}-\mathrm{CO}-\mathrm{OR}$

\section{Derivatization.}

This is a common technique applied in LLE and chromatographic methods. For compounds such as alcohols, phenols and carboxylic acids, the method used is alkylation to form the corresponding ester. The new compound is less water soluble and more soluble in the SF.

There are two methods:

1) In situ derivatization. The alkylation takes place in the matrix.

2) The derivatizing agent is mixed with the $\mathrm{CO}_{2}$, the mixture is allowed to be in contact with the matrix (static extraction) followed by a dynamic extraction. The agent 
should be soluble in $\mathrm{CO}_{2}$. Alkylation under conditions involving phase transfer between water and a water immiscible organic solvent has been established as an efficient method to convert acidic substances to less polar alkylated derivatis.

\subsection{3 $\mathrm{CO}_{2}-$ Water system}

A knowledge of the mutual miscibilities between water and $\mathrm{CO}_{2}$ is important for the extractions.

1) From the extraction efficiency point of view, it has been noted that water can enhance the solubility of polar compound in the SF phase. Macnaughton et al. (1994) reported that the solubility enhancement of 2,4 D is about $96 \%$. However, for DDT, a nonpolar compound, the presence of water in the SF region had no effect. Daneshfar et al. (1995) reported that the recovery of phenoxyacetic acid and phenoxy benzoic acid increased with increasing temperature at constant pressure, possibly due to a greater water content in the SF phase.

2) From the technical point of view, the solubility of water in the SF is a potential problem when collecting the extract. It causes plugging of the restrictor during adiabatic expansion. Another aspect is the incompability of SFE with gas chromatography in the presence of water, if silica columns are used.

Macnaughton et al (1994) obtained the mole fraction of water in the supercritical $\mathrm{CO}_{2}$ as a function of pressure. The data are compared with those obtained by King et al. (1992) and Wiebe et al. (1941). There is good agreement between data (Figure 2.2). The Inole fraction of water in the $\mathrm{CO}_{2}$ rich phase increases as the pressure increases; a higher 
mole fraction is obtained at higher temperatures (comparing the $313.1 \mathrm{~K}$ isotherm with 333.1 $\mathrm{K}$ isotherm).

King et al.(1992) showed that the solubility of liquid $\mathrm{CO}_{2}$ in the water rich phase decreases with an increase in temperature (at constant p) but increases when increasing the pressure (at constant $\mathrm{T}$ ). It is obvious that the higher density of the water-rich phase will be found at low temperatures and high pressures (Figure 2.3). The density of the $\mathrm{CO}_{2}$ rich phase was found to be the same as the pure $\mathrm{CO}_{2}$ (no data shown). 


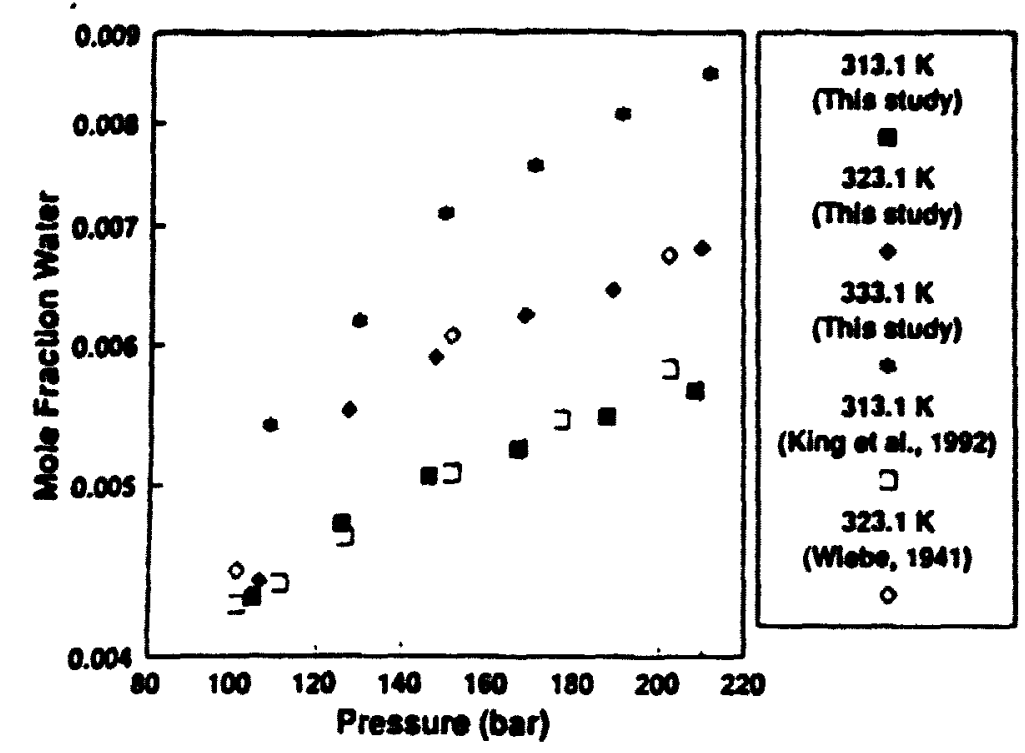

Figure 2.2 Solubility of water in supercritical $\mathrm{CO}_{2}$ as a function of pressure (from Macnaughton et al., 1994).
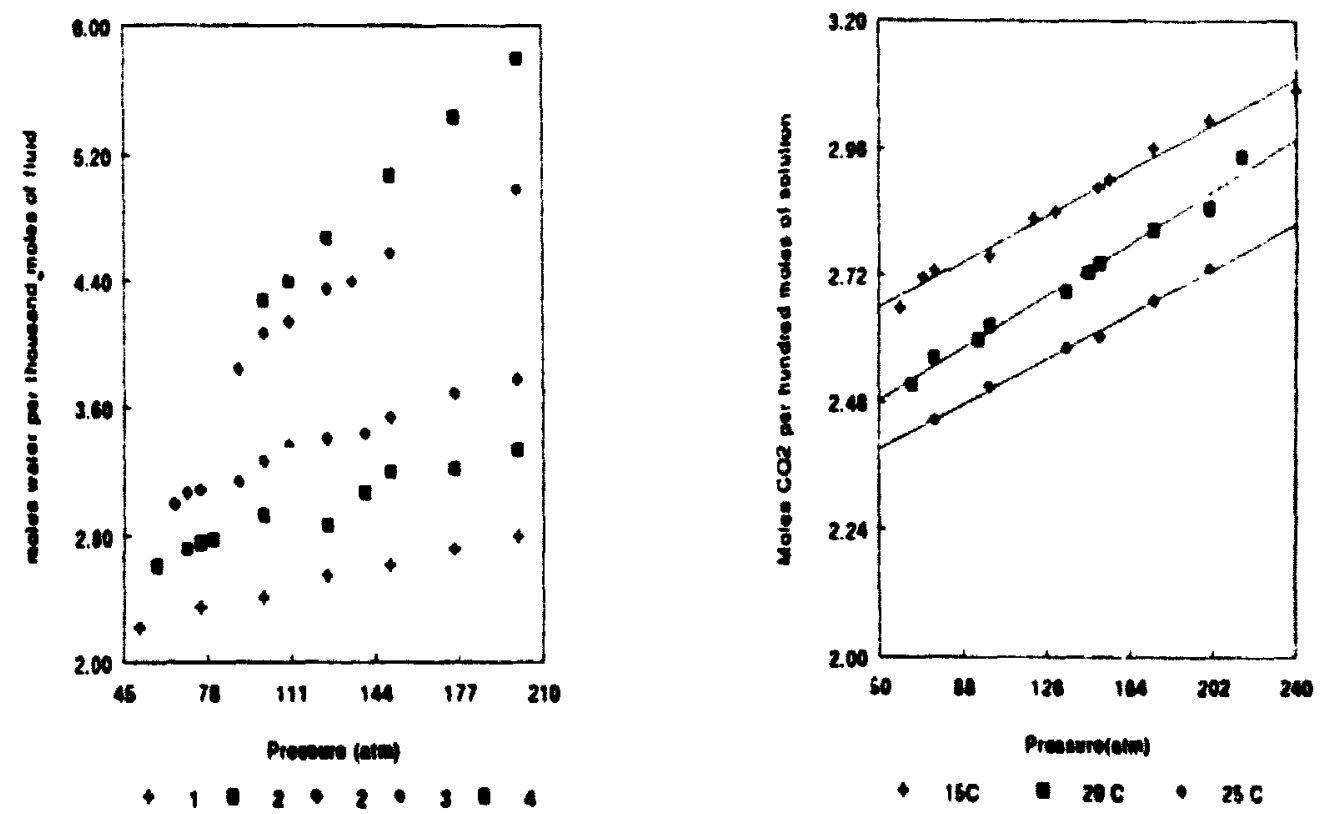

Figure 2.3 Mutual solubilities of water with supercritical and liquid $\mathrm{CO}_{2 .}$ a) solubility of water in liquid and $\mathrm{SFCO}_{2}$ b) solubility of $\mathrm{CO}_{2}$ in water (data from King et al., 1992). 


\subsection{Literature review}

\subsubsection{Partition coefilicients}

Yeo et al. (1990) obtained the partition coefficient of benzene, toluene, naphthalene, and parathion between $\mathrm{SFCO}_{2}$ and water (termary system) and the partition coefficient of the mixture (six component system) at three different pressures $(78.7,89$ and $99.3 \mathrm{~atm}$ ) and two different temperatures (318 and $330 \mathrm{~K}$ ) (Table 2.2).

Based on the results, the authors concluded that:

(1) the value of $K$ increases with an increase in pressure,

(2) the density has more effect on the value of $K$ (density decreases with increasing temperature) than the change in volatility due to the temperature increasing.

(3) the value of $K$ is higher for the six component system that those obtained from the ternary system due to the interactions among the SF, water and the six compounds. They suggested that benzene and toluene acted as entrainers for the extraction of naphthalene and parathion. The $K$ values of benzene and toluene, which are highly soluble in $\mathrm{CO}_{2}$, are of the order of $10^{3}$; this indicates a reduction up to $99.9 \%$ in concentration of the aqueous phase in a single equilibration.

Roop et al. (1990) obtained the partiticn coefficient of a mixture of phenolic compounds for SF/Water (323K) and near-critical fluid/water systems (298 K), and with benzene as entrainer. The mixture contained 2-methoxyphenol, 2-methylphenol, 2,3dimethylphenol, methoxy-methylphenol, phenol and an unidentified compound. 
Partition coefficients were obtained by analyzing the total organic content (TOC) of sample at the end of the extraction The values of $K$ range from 2.43 at 68 atm to 5.7 at 272 atm (see Appendix 5 for pressure unit conversion).

Table 2.2 Summary of partition coefficients from different references.

\begin{tabular}{|c|c|c|c|c|}
\hline Compound & $\begin{array}{l}\text { pressure } \\
\text { (atm) }\end{array}$ & $\begin{array}{l}\text { Temp. } \\
\text { (K) }\end{array}$ & $K^{(I)}$ & Reference \\
\hline Benzene & 99.3 & 318 & 2756 & Yeo et al. $(1990)$ \\
\hline Toluene & 99.3 & 318 & 5083 & “ \\
\hline Naphthalene & 98.5 & 318 & 347 & “ \\
\hline Parathion & 99.3 & 318 & 18 & “ \\
\hline Phenol & 100 & 321 & less than 0.1 & Hedrick et al. (1992a) \\
\hline Phenol & 108.8 & 313 & 1 & Ghonasgi et al.(1991a) \\
\hline Phenol & 108.8 & 313 & 1 & Ghonasgi(1491b) \\
\hline m-cresol & 108.8 & 313 & 1 & " \\
\hline p-chlorophenol & 108.8 & 313 & 3 & “ \\
\hline Benzene & 108.8 & 313 & 3810 & “ \\
\hline 1,2-Dichloroethane & 108.8 & 313.2 & $|4|$ & “ \\
\hline $\begin{array}{l}\text { 1,1,2- } \\
\text { trichloroethane }\end{array}$ & 108.8 & 313.2 & 24 & Sengupta et al.(1994) \\
\hline $\begin{array}{l}\text { 1,1,2,2- } \\
\text { tetrachloroethane }\end{array}$ & 108.8 & 313.2 & 63 & “. \\
\hline 2,4-dichlorophenol & 109.5 & $31:$ & 14 & Akgerman et al (1994) \\
\hline
\end{tabular}

The $K$ values have boes roundad to the expected if alfican fis ires 
Hedrick et al. (1992a) obtained the distribution coefficient of phenol at different pressures and temperatures. The system was a supercritical fluid extraction coupled with supercritical fluid chromatography (SFE/SFC). A 15 minute static extraction was used. For each set ( $T$ and $p)$, five replicates of $20 \mu \mathrm{L}$ of sample $(\mathrm{SF}+$ phenol) were injected in the SFC system. The amount of phenol in the water sample was calculated by mass balance. Values of $K$ range from $0(100 \mathrm{~atm})$ to $0.6(307 \mathrm{~K}$ and $350 \mathrm{~atm})$ (Figure 2.4).

Ghonasgi et al. (1991) obtained values of $K$ for phenol. The comparison of the data obtained by Ghonasgi and Hedrick are shown in table 2.2. The value of $K$ for phenol obtained by Hedrick et al. is one order of magnitude smaller that those obtained by Ghonasgi et al. It could be that $15 \mathrm{~min}$ was not enough time to reach the equilibrium.

Akgerman et al. (1994) reported the distribution coefficient of 2,4-dichlorophenol at two different temperatures and three different pressures. At each $T, K$ increases with $p$. The data were fitted by the use of the Peng-Robinson EOS. The authors claim that the model explains the data; however, no goodness of fit was given. Moreover, only three values for each isotherm were given.

In conclusion the value of $\boldsymbol{K}$ depends on:

1) the density of the fluid; the higher the density the larger the value of $K$,

2) the vapour pressure of the solute,

3) interaction between solute-matrix, solute-SF and solutes (for mixtures). 


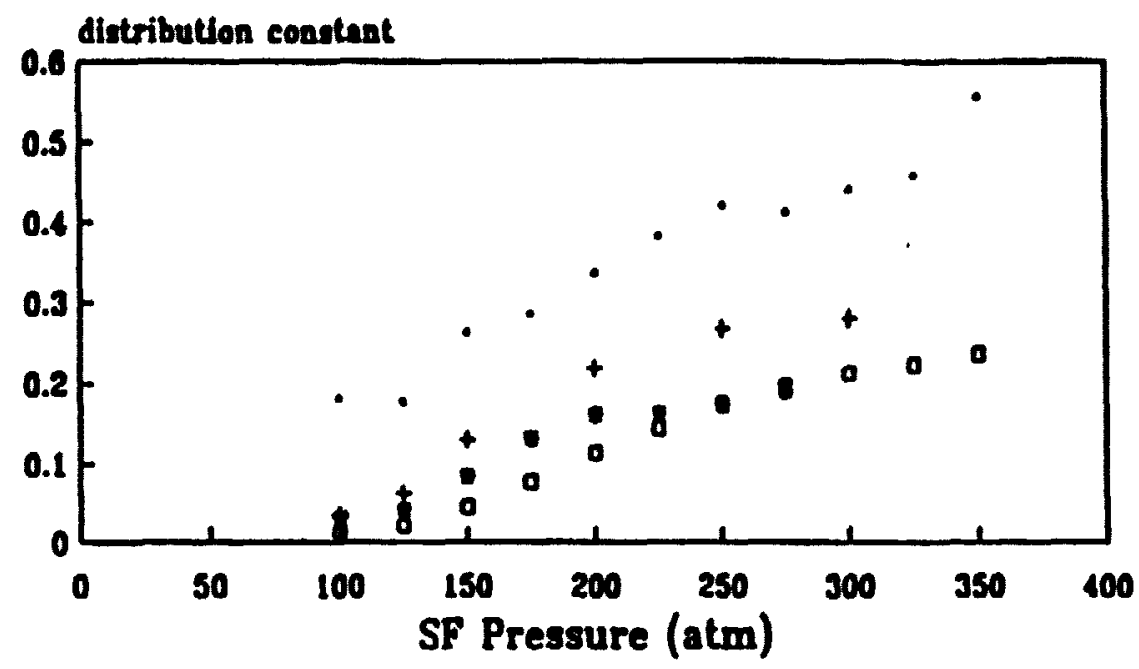

Sjutem Temperature

- $34 \mathrm{C}+48 \mathrm{C} \cdot \mathrm{s4C} \cdot 76 \mathrm{C}$

Figure 2.4 Experimental values of $K$ for phenol at different temperatures and pressures. 
Values of $\boldsymbol{K}$ for different compounds have been obtained experimentally at different pressures and temperatures. By knowing the $K$, trencis in extraction efficiencies could be predicted. For compounds with high $K$ (in the order of $10^{3}$ ) extraction efficiencies would be higher than those compounds with values of $K$ of the order of $10^{\circ}$. In the case of phenols, it would be expected to have recoveries in the following order:

\section{4-dichlorophenol > p-chlorophenol > phenol}

\subsubsection{Direct supereritical fuid extractions}

In a design of an extraction apparatus, the aspects that must be considered are: mass transfer between phases, phase separation and collection of the solute.

The SFE apparatus will be described in terms of the extraction vessel, the restrictor and the trap.

\subsubsection{Extraction vessed}

For direct extraction from water, mutual contact between phases is necessary; therefore, the extraction vessel design plays an important role.

Ghonasgi et al. (1991a, 1991b) described a continuous-flow apparatus (Figure 2.5). The extraction cell consisted in a static mixer followed by a windowed cell separator which allowed observation of the phase separation. Both cells were kept in a constant temperature water bath. By opening two micrometering valves, one from the top (SF) and 
another from the bottom (liquid), the phases were allowed to depressurize forming two phases each; i.e. four phases were generated.

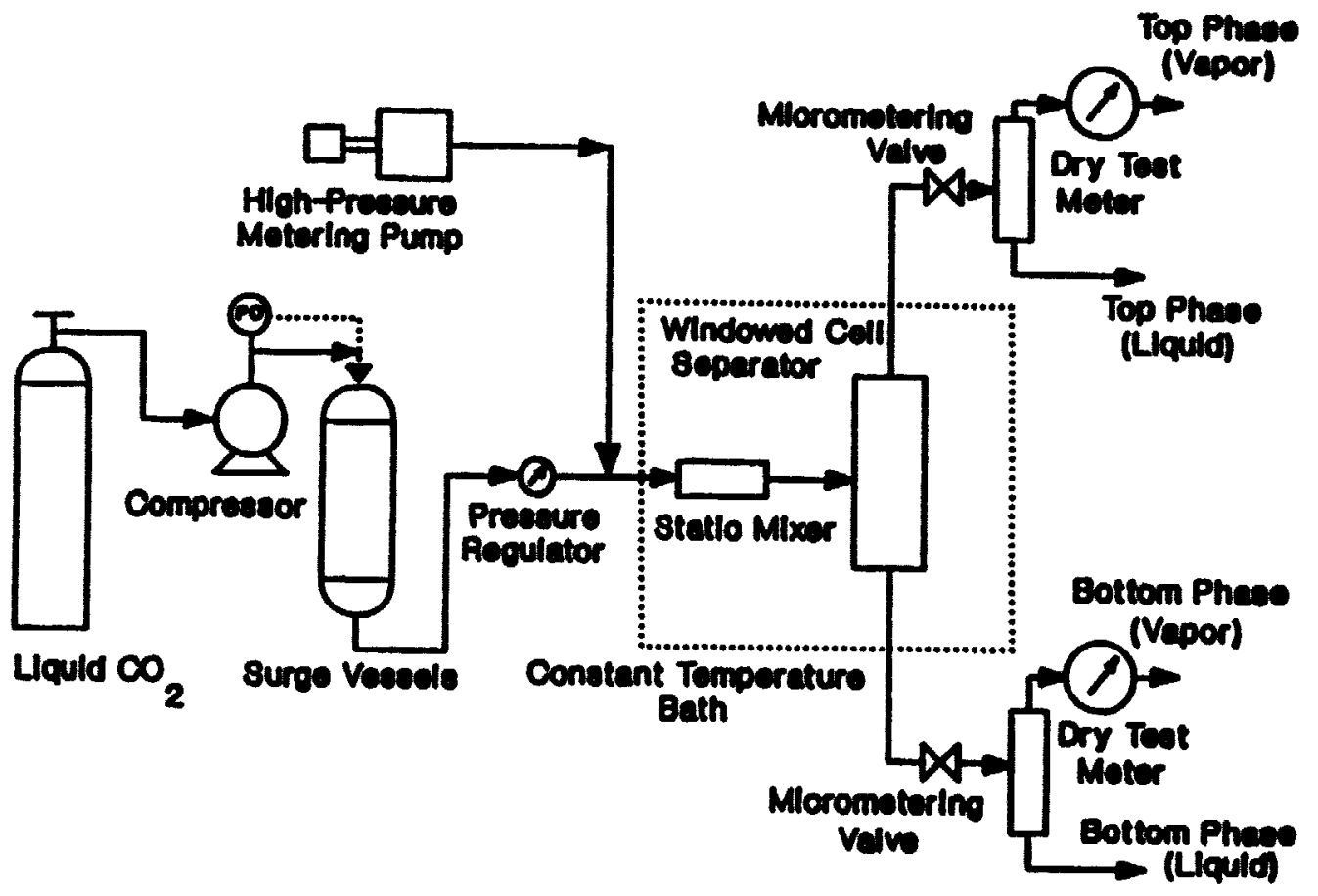

Figure 2.5 Supercritical fuid-liquid equilibrium apparatus from Ghonasgi et al., 1991). 
Once the extraction started, the liquid level in the cell was kept steady by adjusting the lower micro-metering valve. It was reported that the steady state was reached at $\mathbf{4 5}$ $\min$.

The mixing conditions are of importance for the mass transfer to take place, but details of the mixer and the time of mixing are not given. The inconvenience of this apparatus are:

(1) it takes a long time to reach the steady state, and

(2) the system is inadequate for high volatile compounds. The authors thus obtained the mass balance of benzene to within $10 \%$.

Hedrick et al. (1992b) used an extraction vessel with an internal volume of 6.94 $m L$. The zero dead volume channel at either end of the stock vessel was drilled out to a diameter of 1/16". The stainless steel frits that were contained as an integral part of the fitting seal were punched out so that 1/16" stainless steel could pass freely through either end of the vessel. Both the stainless steel inlet and outlet tubes were extended to $1 \mathrm{~cm}$ of the extremes and had an internal diameter of 0.01 in. The sample was placed in the vessel and the SF was introduced from the top of the vessel allowing the phases to be in contact (Figure 2.6a). The extractions were performed with $3 \mathrm{~mL}$ of sample at a flow rate of 1 $\mathrm{mL} / \mathrm{min}$.

Using this extraction vessel, Hedrick et al. (1992b) obtained the extraction profiles for five phenols at $50^{\circ} \mathrm{C}$ at different pressures. They found that the efficiency of the extraction decreases with increasing pressure (density). They suggested that the results 
can be explained by the size and number of $\mathrm{CO}_{2}$ droplets formed, as $\mathrm{CO}_{2}$ diffusivity decreases with increasing pressure.

The size of the drop will be larger and therefore result in a lower interfacial area. Similarly, as pressure increases the density of $\mathrm{CO}_{2}$ is similar to the water. The $\mathrm{CO}_{2} /$ water boundary forms less effectively as the density of $\mathrm{CO}_{2}$ approaches that of water, thereby making mass transfer more difficult (Figure 2.7).

Hedrick et al. (1992a) extracted five phenols from water; their results and conclusions are:

(1) the extraction efficiencies ranked as follows: 2,4 DCP $>2$ chlorophenol $>2,4$ dimethylphenol > 3-methyl,4-chlorophenol > phenol

(2) at the extraction condition all the phenols are in the protonated form; therefore the extraction efficiency was correlated with vapour pressures.

Hedrick et al. (1992b) described the direct extraction of nitrogenous bases (succinonitrile, 2,5-lutidine and picolinic acid) from water and from water containing sodium chloride. No recoveries were achieved at the experimental conditions used; no data are provided. They attempted to extract caffeine and nicotine; they claimed that caffeine was successfully extracted, but not nicotine. They performed extraction of larger organic bases (triprolidine, pseudoephedrine and sulfamethazine). The recovery of sulfamethazine was $\mathbf{9 5 \%}$. No further data are reported. The partition coefficient of amines depend on their basicity and the chain; the longer the chain attached to the nitrogen, the better the extraction. 
$\cos$,
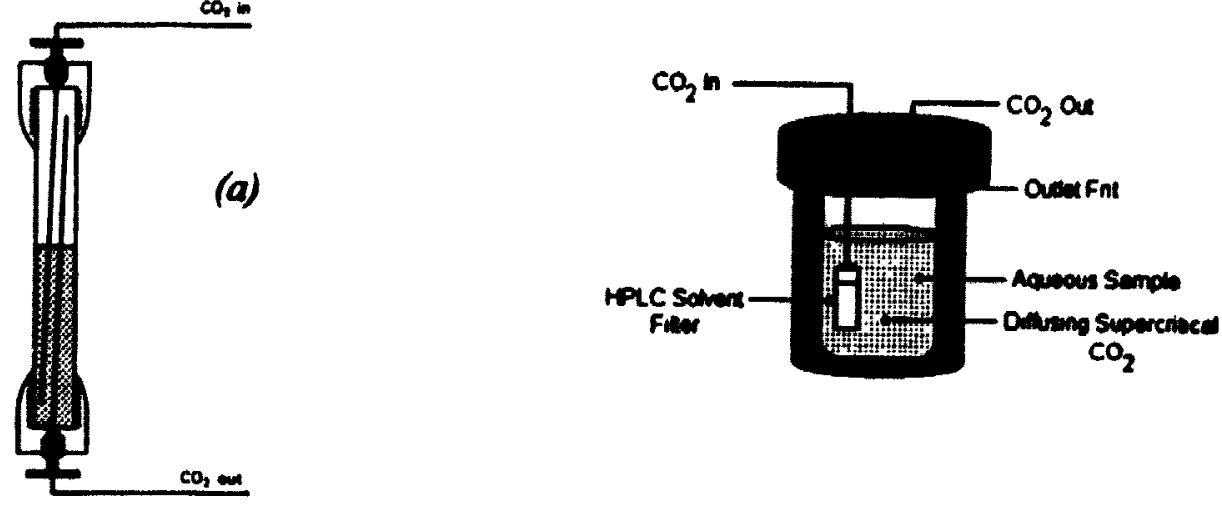

(b)

Figure 2.6. Fxtraction vessel for SFE from aqueous samples (a) Hedrick et al., 1992 and (b) Barnabas et al., 1994.

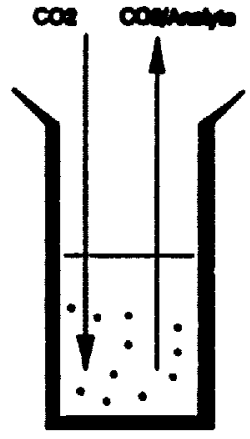

Low Density (small drubbles)

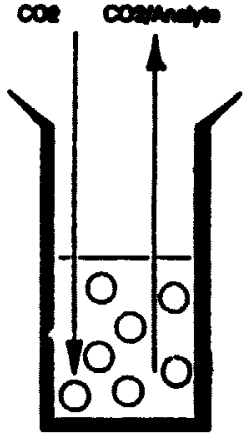

High Density (large drubbles)

Figure 2.7 Representation of liquid-fluid extraction at low and high $\mathrm{CO}_{2}$ density. 
Daneshfar et al. (1995) extracted phenoxyacetic and phenoxybenzoic acid from water. They used a $\mathrm{SFCO}_{2}$ flow of $0.3-0.4 \mathrm{~mL} / \mathrm{min}$. The volume of $\mathrm{SFCO}_{2}$ necessary to obtain a complete extraction was 6 times the volume of the sample $(30 \mathrm{~mL} \mathrm{SFCO} / 5 \mathrm{~mL}$ of sample).

At constant temperature $\left(60^{\circ} \mathrm{C}\right)$, the efficiency of the extraction increased as the pressure increased from $150 \mathrm{~atm}$ to $300 \mathrm{~atm}$, i.e. higher efficiencies at higher densities $(0.62 \mathrm{~g} / \mathrm{mL}$ vs. $0.837 \mathrm{~g} / \mathrm{mL})$. This is in contrast to the results of Hendrick et al., $1992 \mathrm{a}$. They reported efficiencies of $99 \%$ and $98 \%$ for phenoxyacetic acid and phenoxybenzoic acid respectively. The efficiency of extractions performed at constant pressure (200 atm) increased with an increase in temperature. They suggested that at higher temperatures the solubility of water in $\mathrm{SFCO}_{2}$ increases and thus the solubilities of the analytes in the modified supercritical $\mathrm{CO}_{2}$ increases, even though the density of the $\mathrm{SF}$ decreases.

Barnabas et al. (1994) designed a "headspace" extraction cell (Figure 2.6b) with an internal volume of $50 \mathrm{~cm}^{3}$. The inlet tube had a HPLC solvent filter at the end $(10 \mu \mathrm{m}$ frit). The purpose of the filter is to aid mixing of the sample with the SF. The headspace configuration allows the SF to pass through the aqueous sample before exiting the vessel. Samples of $45 \mathrm{~mL}$ were used in the extraction.

Barnabas et al. (1994) extracted lindane, aldrin and dieldrin from water samples at different flow rates $(0.7,1.0$ and $1.5 \mathrm{~mL} / \mathrm{min})$. They performed a SPE-SFE extraction as well. They found that:

(1) the flow rate had little effect on the recoveries, 
(2) the number of cell volumes swept for the three flow rates were : $0.9,1.3$ and 1.9 , but the maximum recovery was $70 \%$

(3) the overall recoveries for the direct extraction are in the order of $20 \%$ lower than the SPE-SFE extraction. This may be due to the poor diffusion of the SF $\mathrm{CO}_{2}$ through the aqueous matrix

Shimoda et al. (1994) repored the extraction of aicohols, aldehydes and esters from $0.3 \%$ aqueous solution of sugar ester. The $120 \mathrm{~mL}$ extraction vessel had a cylindrical filter made of stainless steel with a pore size of $10 \mu \mathrm{L}$. Although the authors did not show the vessel, it seems that is the same as that used by Barnabas et al. The recoveries of acids and miscible water compounds were $>90 \%$. They pointed out the importance of knowing the bubble size since the rate of mass transfer through boundary phases could then be calculated.

Brewer et al. $(1993,1994)$ described an extraction vessel which increased the water-SF interface by introducing the SF through a disk with small holes. The "drubbler" allowed the formation of drubbles (droplets/bubbles) (Figure 2.8), increasing the interface area. Two vessels able to contain $25 \mathrm{~mL}$ and $75 \mathrm{~mL}$ of sample were built. Extractions of PCP were performed with the drubbler and without it. Exhaustive PCP extraction with the new vessel showed recoveries of $97 \%$. The extraction efficiencies with the new vessel were 1.6 times higher than without the drubbler. Moreover, extractions were found to be essentially complete when the volume of $\mathrm{SFCO}_{2}$ was 1.5 times the volume of sample. The extractions were not affected by the density. 

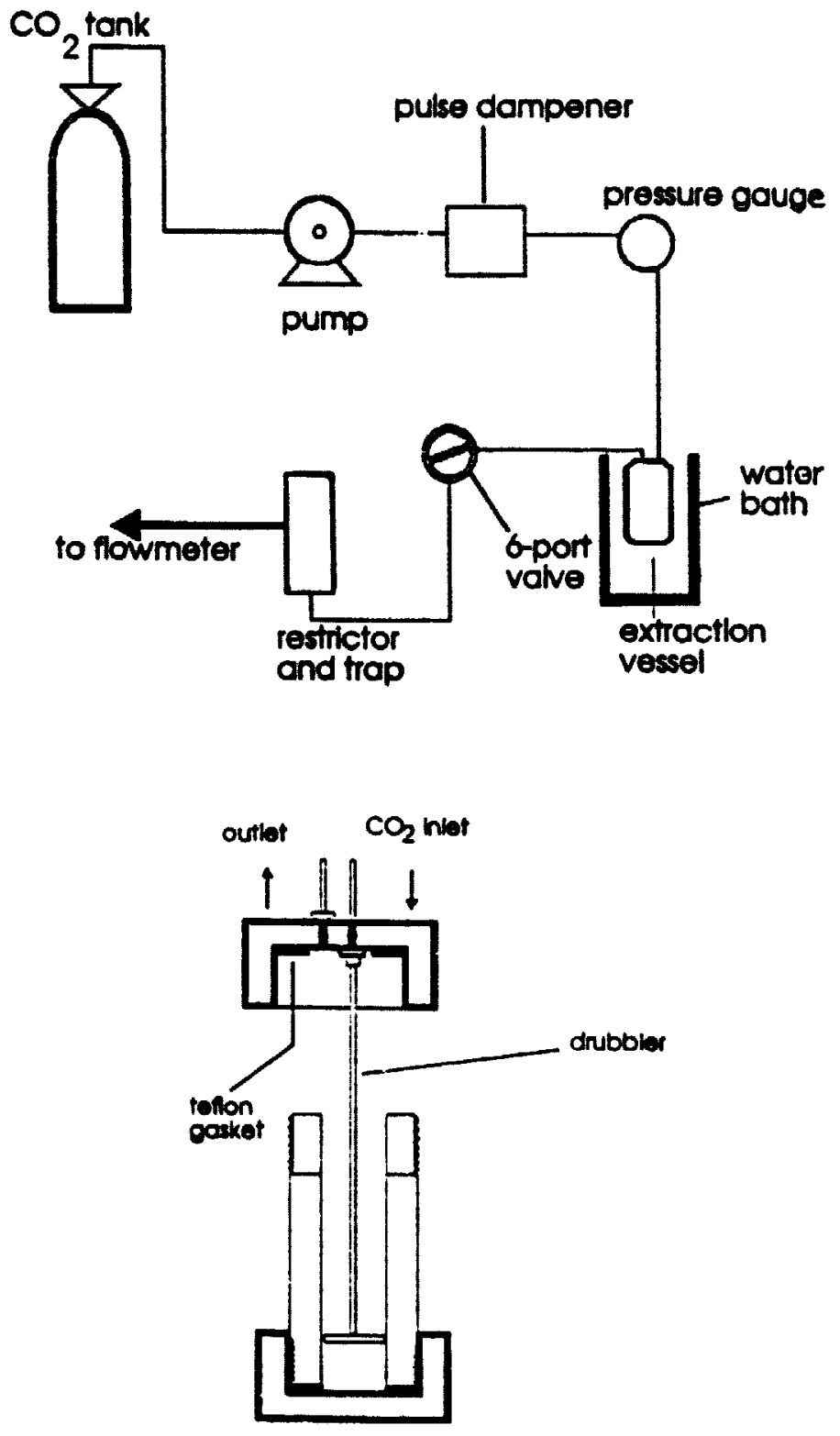

Figure 2.8 Extraction vessel and drubbler (From Brewer et al., 1993). 
The authors modeled hydrodynamics of the extraction vessel. The mass transfer occurs at the drubbles' interface. The size and number of the drubbles and the time of contact ( the rate of rise of the drubbles up the water column ), are thus of importance. They found that at the experimental conditions used, a turbulent flow occurred around the rising drubbles.

Chang et al. (1995) described a semicontinuous supercritical apparatus system (Figure 2.9). The extractor is formed by three stainless steel seamless tubes $(20 \mathrm{~cm}$ in length and $1.2 \mathrm{~cm}$ i.d). The extractor was filled with stainless steel wire-mesh rings (200 mesh) to improve mass transfer between phases. A sample of $60 \mathrm{~mL}$ was placed as follows: $25 \mathrm{~mL}$ in the two first columns and $10 \mathrm{~mL}$ in the last column. After reaching the desired temperature, the $\mathrm{CO}_{2}$ was pumped to the extractor; the equilibration time was 90 min. After 30 min the semicontinuous flow extraction started. Samples were collected

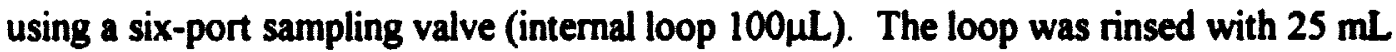
distilled water and collected in $25 \mathrm{~mL}$ volumetric flasks for analysis (HPLC). 


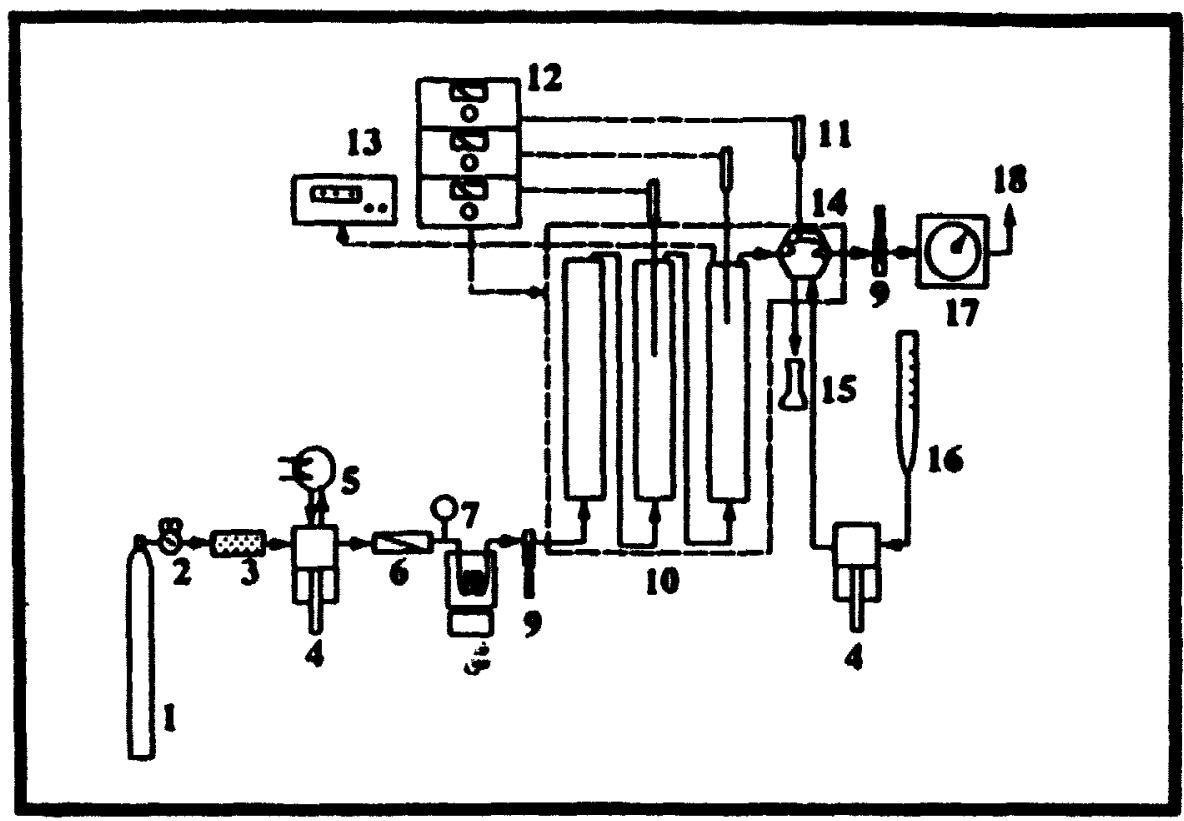

\begin{tabular}{|c|c|c|}
\hline $\begin{array}{l}\text { ges cylinder } \\
\text { regulator } \\
\text { rilier } \\
\text { metering pump } \\
\text { cooler } \\
\text { check valve } \\
\text { pressure gauge } \\
\text { pre-heater }\end{array}$ & $\begin{array}{l}9 \\
10 \\
11 \\
12 \\
13 \\
14 \\
15 \\
16 \\
17 \\
18\end{array}$ & $\begin{array}{l}\text { metering valve } \\
\text { constant temperature extractor } \\
\text { thermocouple } \\
\text { temperature controller } \\
\text { digital pressure transducer } \\
\text { six-port valve with a 100pl bop } \\
\text { eampling rlask } \\
\text { glass burette } \\
\text { wet ges meter } \\
\text { vent }\end{array}$ \\
\hline
\end{tabular}

Figure 2.9 Schematic flow diagram of semicontimuous supercritical fluid extraction system (from Chang et al., 1995). 


\subsubsection{Restrictors}

In depressurizing the system, as a result of adiabatic expansion, the restrictor cools down and the extracted solutes can precipitate out causing blockages. Some methods to minimize this are:

(1) heating the restrictor,

(2) minimizing the pressure drop between the extraction vessel and the end of the restrictor, e.g. by using a sudden pressure drop at the end, and

(3) using a restrictor able to work under high flow rates.

The most commonly used restrictor is the fused silica capillary restrictor. The flow rate depends on its length and internal diameter. The shorter the length and the larger the i.d., the higher the flow. Whenever the linear restrictors are used, it is important to take into account that there is a drop in pressure along the capillary and blockage can take place inside the restrictor causing it to break. The pressure drop along the capillary can be expressed by the Hagen-Poiseuille equation when the flow is laminar:

$$
\frac{\Delta p}{m}=\frac{8 L}{\pi \rho R^{4}} \eta
$$

Here $L$ is the length of the capillary over which pressure drop $(4 p)$ is measured, $m$ is the mass flow rate, $\rho$ is the fluid density, $R$ is the radius of the capillary, and $\eta$ the viscosity. 


\subsubsection{Trapping System}

There are two main methods of collecting the solute after depressurization of the $\mathrm{CO}_{2}$ :

1) A liquid trap, where the restrictor is submerged in a suitable solvent. The disadvantages of this system are that at high flow rates aerosol formation has been reported, and loss of more volatile compounds can occur.

2) A solid trap, where the analyte is trapped in solid phase. This could be a tube packed with diol, cyano, amino, phenyl, C18 as reported by Hedrick et al. (1992), a stainless steel tube (Brewer et al. 1993), or a container with stainless steel spheres (Hewlett Packard).

Some systems couple SFE directly with chromatography and e.g. cryotrap the solute as in Purge and Trap techniques. 
Chapter 3 


\section{EXPERIMENTAL}

\subsection{Experimental Design}

The main objectives of this work were

(1) to assess the efficiency of supercritical fluid extraction (SFE) as compared to that obtained by two conventional methods, liquid-liquid (LLE) and solid phase extraction (SPE); and

(2) to evaluate the sensitivity of the aforementio, ird techniques to the presence of fulvic acids.

Therefore, a two factorial experiment design was selected. The first factor (method) contained three levels which represent the hind of extraction: LLE, SPE and SFE; the second factor (sample) contained two levels: PCP spiked into deionized water and PCP spiked into FA solution (see sample preparation).

Finally, the ultimate objective was to apply supercritical fluid extraction to real water samples when these are spiked with PCP.

Some further feasibility axperiments were made in order to make supercritical fluid extraction easier to perform and to reduce the time of the analysis. The description of these experiments will be discussed below. 


\subsection{Sample Preparation}

\subsubsection{Pentachlorophenol stock solution.}

A stock standard solution was prepared by weighing accurately (three significant figures) $0.04 \mathrm{~g}$ of PCP ( $98 \%$ purity) and transferring it to a $100 \mathrm{~mL}$ volumetric flask. Methanol (HPLC grade, Fisher) was added up to the mark. The solution was mixed thoroughly and stored at $4^{\circ} \mathrm{C}$ in the dark prior to its use.

\subsubsection{Fulvic acid stock solution}

The fulvic acid used in this study was obtained from the Department of Water and Environmental Studies in Lipköping, Sweden. The number average molecular weight was $M_{n}=1190$, the weight average molecular weight was $M_{w}=1810$. It came originally from the Oulopki River, Finland.

The stock solution was prepared by weighing $0.0400 \mathrm{~g}( \pm 0.0001 \mathrm{~g})$ of fulvic acid, placing it in a $200 \mathrm{~mL}$ volumetric flask and filling up to the mark with deionized water. The solution was shaken thoroughly and stored at $4^{\circ} \mathrm{C}$ prior to its use.

\subsubsection{PCP in deionized water (PCP/W)}

PCP in water was prepared by spiking deionized water with the stocix solution to give a PCP final concentration of $0.200 \mathrm{mg} / \mathrm{L}( \pm 0.002)$. The solution then contained $0.05 \%(v / v)$ of methanol. The solution was stirred in the dark for 24 hours and stored at $4^{\circ} \mathrm{C}$ until extraction. 


\subsubsection{PCP in fulvic acid solution (PCP/FA)}

PCP in fulvic acid was prepared by spiking fulvic acid solution (concentration of fulvic acid of $20 \mathrm{mg} / \mathrm{L}$ ) with a PCP stock solution to give a final concentration of PCP of $0.200 \mathrm{mg} / \mathrm{L}$. The solution was stirred in the dark for 24 hours and stored at $4^{\circ} \mathrm{C}$ until use.

As the type of sample was one of the factors in the experimental design , both the PCP/W and PCP/FA solutions were prepared and treated in the same way.

\subsubsection{Real sample}

Sample description

It was considered important to apply the methods to real water samples since these are more complex. The water sample was provided by the Britannia Water Purification Plant. It was obtained from the Ottawa River, which is the main supply of raw water for the Ottawa-Carleton Region. The Municipality of Ottawa-Carleton is responsible for water purification and distribution to the region. Some results of the analysis of raw and treated water are shown in the Tables 1.1 and 1.2 (page 7).

Sample preparation

The sample was spiked with the PCP stock solution, with a volume such that the final concentration was of $0.200 \mathrm{mg} / \mathrm{L}$ of $\mathrm{PCP}$. The solutions were stirred with a magnetic stirrer for 48 hours in the dark and stored in the dark at $4^{\circ} \mathrm{C}$ prior to their use. 


\subsubsection{PCP calibration standards}

Calibration curves were prepared for every set of extractions by taking aliquots from the stock solution to get concentrations of $0,0.50,0.75,2.25$ and $4.25 \mathrm{mg}$ of PCP/L.. The solvent was methanol.

\subsection{Supercritical fluid extractions (SFE)}

\subsubsection{SFE using a solid phase trap}

Apparatus description.

The apparatus used was described by Brewer et al. (1993) (Figure 3.1). The $\mathrm{CO}_{2}$ was supplied as liquid, $99.5 \%$ purity ( $\mathrm{CO}_{2}$ high pressure liquid, BOC Gas). The cylinder was connected to the pump ( mini Pump $\Theta$, Milton Roy); the pump head was chilled with glycol solution at $0^{\circ} \mathrm{C}$. The pump was connected to a pressure gauge (Span Instruments 0-6000 psi) through a $1 / 8^{\prime \prime}$ o.d. stainless steel tube. Valve 1 (Autoclave, engineers, max. pressure 11,000 psi) was placed between the pressure gauge and the extraction vessel, which was placed into a water bath to get the desired temperature. A second valve (Valve 2) was placed between the extraction vessel and the restrictor. The restrictor was a $1 / 16^{\prime \prime}$ o.d. tube crimped at its end, and it was placed inside the trap (a flattened, coiled 1/4 " o.d. stainless steel tube, internal volume $5 \mathrm{mi}$ ). The initial part of the tubing and the restrictortrap was heated with an electric heater while the flat part of the trap was placed in ice. The end of the trap was connected to the bubble flowmeter (Figure 3.1b). The flow was monitored every $15 \mathrm{~min}$. 
(a)

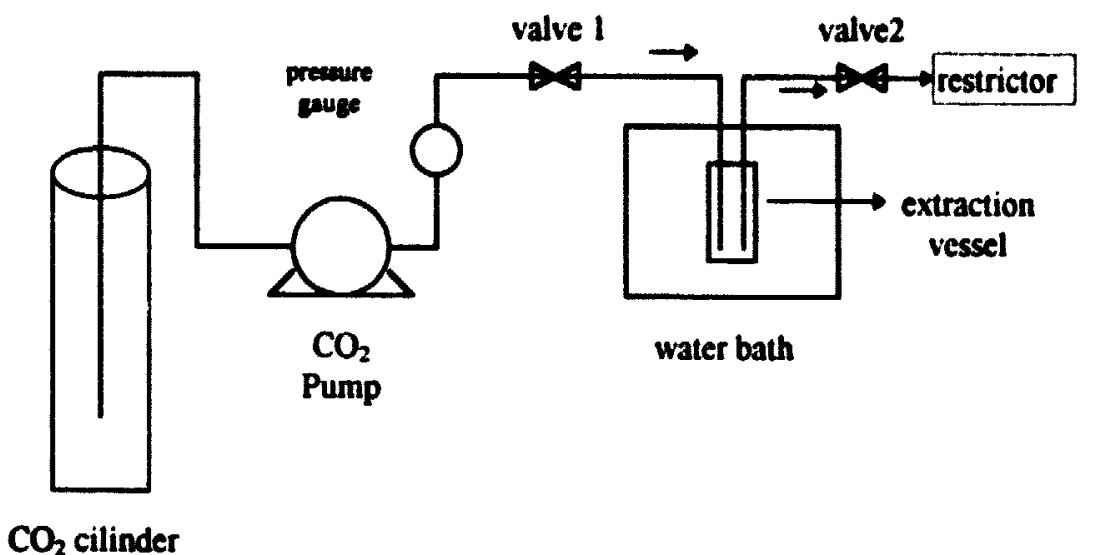

(b)

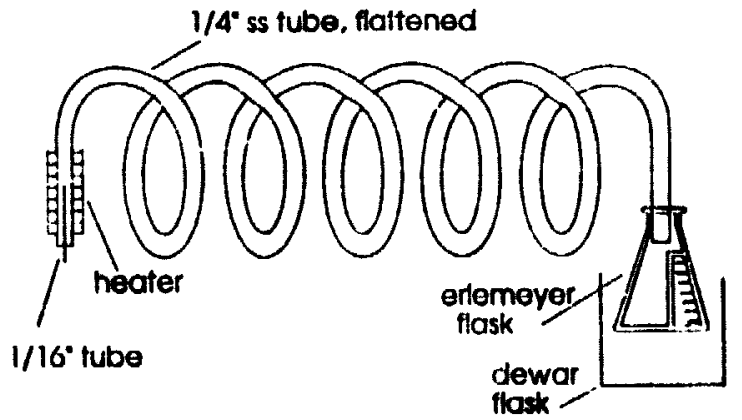

Figure 3.1 a) Supercritical fluid extraction apparatus b) solid phase trap (Brewer, 1995). 
All the stainless steel tubing used was supplied by Chromatographic Specialties Inc. It was suitable for pressures up to $10000 \mathrm{psi}$. The experiments were done at 3000 psi (see Appendix 5 for unit conversion).

\section{Extraction.}

The sample $(20 \mathrm{~mL} \pm 0.03 \mathrm{~mL})$ was placed in the extraction vessel which was connected to the system and placed in the water bath at $40^{\circ} \mathrm{C}\left( \pm 1^{\circ} \mathrm{C}\right)$. With valve 2 closed, valve 1 was opened and the vessel was allowed to reach thermal equilibrium (20 min). Then the pump power switch was turned on to its maximum flow until the desirable pressure was reached (3000 psi); this took about 3 minutes. At this time valve 2 was opened. The micrometer stroke was then adjusted to get a constant pressure. The dynamic extraction started as soon as valve 2 was opened.

The time of extraction was dependent on the flow; it was calculated to have $20 \mathrm{~mL}$ of SF $\mathrm{CO}_{2}$ flow through the water. In some cases, after $20 \mathrm{~mL}$ had flowed through, the trap was replaced by a second trap and another $20 \mathrm{~mL}$ of $\mathrm{SFCO}_{2}$ were passed through. Once the extraction was finished, the pump was tumed off. The trap was removed and rinsed with two sets of $1 \mathrm{~mL}$ volumes of methanol countercurrent to the SF flow. The solution obtained was placed in a preweighed vial. 


\subsubsection{Supercritical Fluid Extraction with the fused silica capillary reatrictor.}

The apparatus used was the same as described in section 3.3 .1 but the restrictor and trap were changed. The restrictor (Figure 3.2a) was described by Burk (1990), and consisted in a fused silica capillary ( $41 \mu \mathrm{m}$ i.d $\times 30 \mathrm{~cm}$ length) connected to the system with a 1/16" Swagelock and a graphite ferrule. Part of the tubing and capillary were heated with an electric heater and ceramic insulators. The end part of the capillary $(2 \mathrm{~cm})$ was submerged in methanol contained in a vial. The vial was immersed in a water bath at room temperature. Earlier experiments showed aerosol formation, and part of the methanol was trapped in the bubble flow meter. To ensure that there was no analyte loss, a Teflon tube was connected from the first vial to a second vial which was placed in an ice bath (Figure 3.2b).

The extraction was performed at $3000 \mathrm{psi}, \mathrm{T}=40{ }^{\circ} \mathrm{C}, \mathrm{SFCO}_{2}$ density $0.85 \mathrm{~g} / \mathrm{mL}$, $\mathrm{SFCO}_{2}$ flow rate of $1.2 \mathrm{~mL} / \mathrm{min}$. This density, as well as those quoted in the report, was obtained from SF Solver program provided by ISCO, Inc., 1992. 
(a)

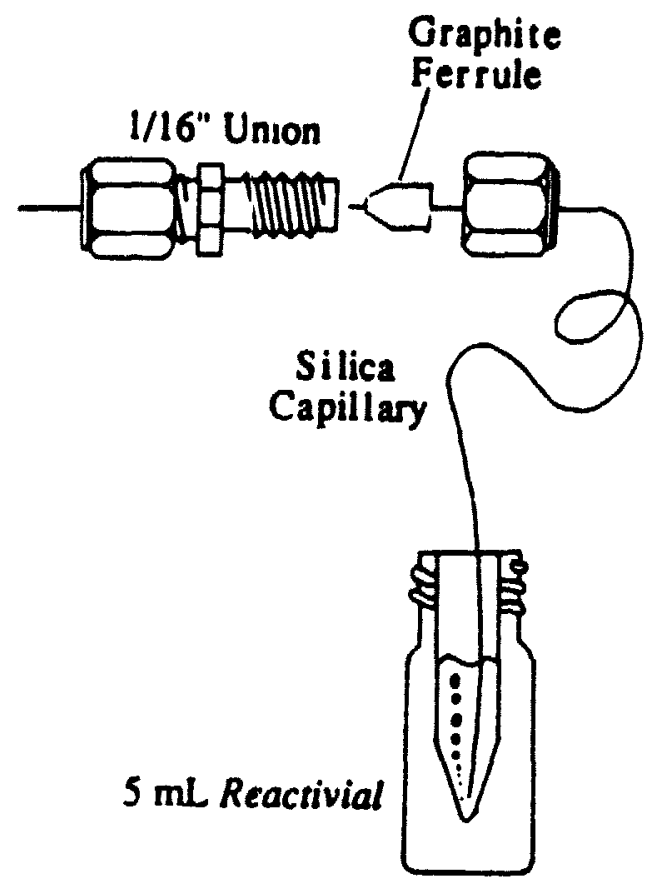

(b)

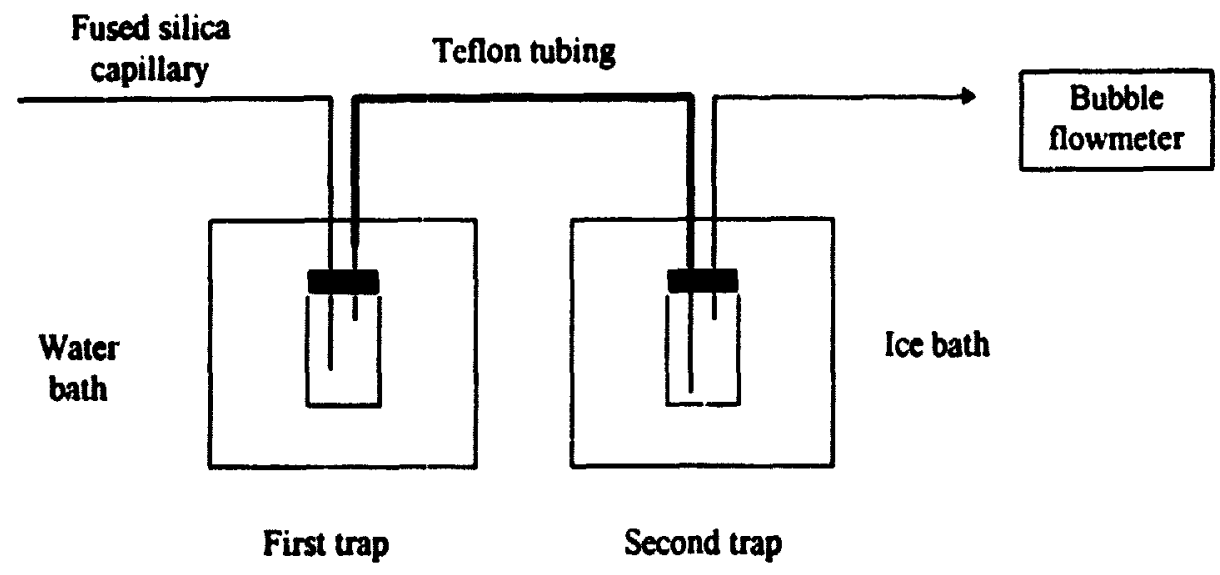

Figure 3.2 Restrictors: a) fused silica capillary (Burk, 1990) b) as used in this study. 


\subsubsection{Supereritical Fluid extraction at different temperatures}

In section 3.3.1 and 3.3.2 (pages 46 and 49 respectively) the apparatus and extractions were described, the extractions condition were at $40^{\circ} \mathrm{C}$ and $3000 \mathrm{psi}$, where. the density of $\mathrm{SFCO}_{2} 0.85 \mathrm{~g} / \mathrm{mL}$.

The density of a supercritical fluid increases as temperature decreases. As the solvent strength is mainly given by the density of the fluid, extractions were performed at 21 and $40^{\circ} \mathrm{C}$ to test the effect of temperature. The pressure was $3000 \mathrm{psi}, \mathrm{SFCO}_{2}$ in all the cases. The volume of $\mathrm{SFCO}_{2}$ was $40 \mathrm{~mL}$ for each extraction.

\subsection{Extractions of PCP/W and PCP/FA}

Although the samples were stored in the dark and at $4{ }^{\circ} \mathrm{C}$ to avoid analyte losses, it was considered necessary to perform a control test as follows: The samples (PCP/W and PCP/FA) were prepared at the same time and under the same conditions. The sample containing PCP in deionized water was extracted by each method (LLE, SPE and SFE) one day and 10 days after its preparation. In doing this, the differences in the recoveries between methods will be due to the presence of FA and not due to the analyte decay. To test this, an analysis of variance was obtained.

\subsubsection{Liquid-liquid extraction (LLE)}

The sample $(20 \mathrm{~mL} \pm 0.03 \mathrm{~mL})$ was placed in a $125 \mathrm{~mL}$ separatory funnel. The sample was acidified with $9 \mathrm{M} \mathrm{H}_{2} \mathrm{SO}_{4}$ to $\mathrm{pH} 2$ and shaken thoroughly. Three successive extractions were performed by shaking the sample with $2 \mathrm{~mL}$ of dichloromethane (HPLC 
grade, Fisher) for 5 min periods. The phases were allowed to separate for $15 \mathrm{~min}$. The extracts were collected in a preweighed vial.

Some problems were encountered in the analysis by HPLC when dichloromethane (DCM) was used; therefore, the sample was allowed to dry in the dark at room temperature and restored with a small amount of methanol. In order to assess the suitability of the drying procedure, for each set of extraction two standards were dried and restored at the same conditions.

\subsubsection{Solid phase extraction (SPE)}

Pentachlorophenol is also analyzed by the 515.2 method dictated by the US Environmental Protection Agency (US EPA); an Empore disk is used for this, with the eluting solvent $10 \%$ methyl-t-butyl ether (MTBE) in methanol. Previous experiments showed difficulties in the use of the HPLC with MTBE present. It was consequently replaced by DCM in the extraction of the disk.

A standard $47 \mathrm{~mm}$ filtering apparatus was used (Millipore). The disk Poly(styrendivinyl-benzene)SDB (Empore ${ }^{\mathrm{TM}}$ ) was place in the apparatus. The disk was conditioned as follows: $10 \mathrm{~mL}$ of acetone was poured into the beaker; the disk was let to soak for $3 \mathrm{~min}$; then vacuum was applied for $1 \mathrm{~min}$. The same was repeated with $10 \mathrm{~mL}$ of DCM; finally, $10 \mathrm{~mL}$ of methanol was poured in, the vacuum was applied but the disk was not allowed to dry. This is the critical step since the extraction relies on how well the disk is wetted. The $20 \mathrm{~mL}$ sample (acidified with $\mathrm{H}_{2} \mathrm{SO}_{4}$ ) was passed through the disk, with the vacuum applied. After drying, the PCP was eluted with $6 \mathrm{~mL}$ of DCM which was 
collected in a preweighed vial. This was allowed to dry in the dark and restored with methanol prior to analysis.

\subsubsection{Supercritical nuid extraction}

Supercritical fluid extraction was performed as described in section 3.3.2. The extraction conditions were temperature: $21^{\circ} \mathrm{C}$, pressure: 3000 psi, $\mathrm{SFCO}_{2}$ flow rate: 1.2 $\mathrm{mL} / \mathrm{min}$, density of the fluid: $0.94 \mathrm{~g} / \mathrm{mL}$.

Profiles of the extractions were obtained as follows: For a single extraction, 20 $\mathrm{mL}$ of $\mathrm{SFCO}_{2}$ was passed through the sample and collected in methanol contained in a vial. The vial was replaced and a further $20 \mathrm{~mL}$ of $\mathrm{SFCO}_{2}$ was passed through the sample. For some extractions this procedure was repeated one more time.

\subsection{Extraction of PCP from real samples}

The extractions (LLE, SPE and SFE) were performed as described in section 3.4. For SFE, no extraction profiles were obtained; exhaustive extraction and collection in one vial was performed. The volume of $\mathrm{SFCO}_{2}$ for the extraction was $40 \mathrm{~mL}$.

\subsection{Analysis}

Pentachlorophenol is often analyzed by methods 515.2 and 515.5 US EPA. In these methods, PCP is extracted with ethyl ether (515.5) or with an Empore disk (515.2) and converted to its ester by using diazomethane. The ester is determined by gas chromatography with electron capture detector (GC/ECD). The inconvenience of this method is that the time of analysis is about $30 \mathrm{~min}$ per sample without taking into account 
the time spent in the derivatization step. On the other hand, HPLC has been successfully used as method of analysis (Brewer, 1994). Therefore, PCP extracted by any method was analyzed by HPLC with methanol as solvent.

The analysis of the extracts was done by high pressure liquid chromatography

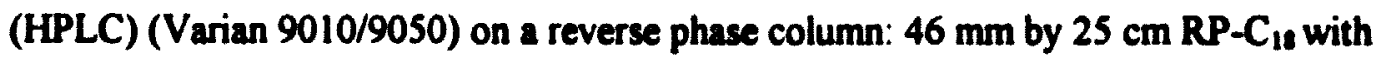
particles size of $5 \mu \mathrm{m}$ (Zorbax) equipped with a guard column of the same packing. The mobile phase was $95 \%$ methanol $5 \%$ (0.5\% acetic acid), with a flow rate $1.5 \mathrm{~mL} / \mathrm{min}$ and a pressure of $130 \mathrm{~atm}$. The detector used was Varian $9050 \mathrm{UV} \cdot \mathrm{Vis}$ detector. The wavelength at which the maximum absorbance is obrained was $224 \mathrm{~nm}$, based on the data reported by Grasselli.

The volume of both standards and samples injected into the column was $30 \mu \mathrm{L}$. At these conditions, the retention time for PCP was $3.0( \pm 0.1) \min ($ see Appendix 1). The standards and samples were injected three times.

The Varian module interactive graphic/Data handling detects a peak and integrates the area under the chromatogram with an algorithm (Varian, 1991). The criteria for the existence of a peak is predetermined by setting the signal to noise ratio to a value of 5 . Any slope equal or higher than 5 was recorded as a peak. The area under the peak is calculated based on the baseline. The area, in counts, is proportional to the concentration of the analyte (see Appendix 2).

In order to quantify the extracts, standards of pentachlorophenol were prepared (see section 3.2.6) and injected followed by the extracts. The calibration curve was 
constructed by plotting the area (average of the three injections) versus the amount of pentachlorophenol injected. A simple linear regression was obtained as well as the equation of the line (See Appendix 2). Neither a surrogate nor an internal standard was added to the extract.

\subsection{Data Analysis}

All the statistical analysis were obtained by Systat 5.01 for Windows.

The linear regression for the calibration curves and calculation of concentration and recoveries were obtained by Quattro Pro (QPRO).

The values of density of the fluid were obtained by SF-Solver (TM) program Isco, Inc., 1992 


\section{Chapter 4}




\section{RESULTS AND DISCUSSION}

\subsection{HPLC Analysis}

The minimum detectable quantity of PCP was determined by setting the signal to noise limit to $\subseteq$. Thus any peak detectable by the instrument was at least five times greater than the noise level of the instrument. Small concentrations of pentachlorophenol were injected. After three injections, the lowest detectable amount was found to be $3.2 \mathrm{ng}$ with a $20 \mu \mathrm{L}$ injection. The volume of sample and standards injected was $30 \mu \mathrm{L}$. The lowest amount injected in these studies was $12 \mathrm{ng}$.

The relative standard deviation obtained (after three injections) increased with decreasing the amount injected (see Appendix 2). Most of the concentration of the extracts were in the region where the \%RSD was of the order of $5-10 \%$. This was confirmed by calculating it from the three injections.

\subsection{Supercritical Fluid Extraction: feasibility studies}

\subsubsection{SFE using a solid phase trap}

At the beginning of the study, the experiments reported by Brewer et al. were reproduced (see extractions, section 3.3.1). The restrictor was 1/16" tube crimpeci at the end and the trap was a flattened coiled $1 / 4 "$ o.d. stainless steel tube.

Due to the Joule-Thompson effect, the tip of any restrict ir cools down; this can cause blockage of the restrictor. Such blocking can be minimized by heating the tip. In 
this system, before the restrictor plugged, only three extractions could be performed consecutively even though the restrictor was heated. The restrictor thus had to be replaced often.

By crimping the tip of the $1 / 16^{\prime \prime}$ tube with an adjustable mirrometer, it was possible to regulate the flow rate. The flow rate was, however, difficult to reproduce. Figure 4.1 shows the \% recovery of $\mathrm{PCP}$ as a function of flow rate; the volume of $\mathrm{SFCO}_{2}$ used was $20 \mathrm{~mL}$. The recovery after 10 extraction was $49 \%$ (\%RSD of 24).

Previous experiments (Brewer et al., 1994) demonstrated that the flow rate had no influence on the $\%$ of recovery; however, the large variance suggested that the flow should have some influence. The data were thus arranged in three groups depending on the flow and analyzed by ANOVA (Appendix IV, Table IV.1 and IV.2). There was no difference between groups; the recovery is thus not influenced by the flow. This is in agreement with a primitive model of the process. 
Recovery as function of flow rate

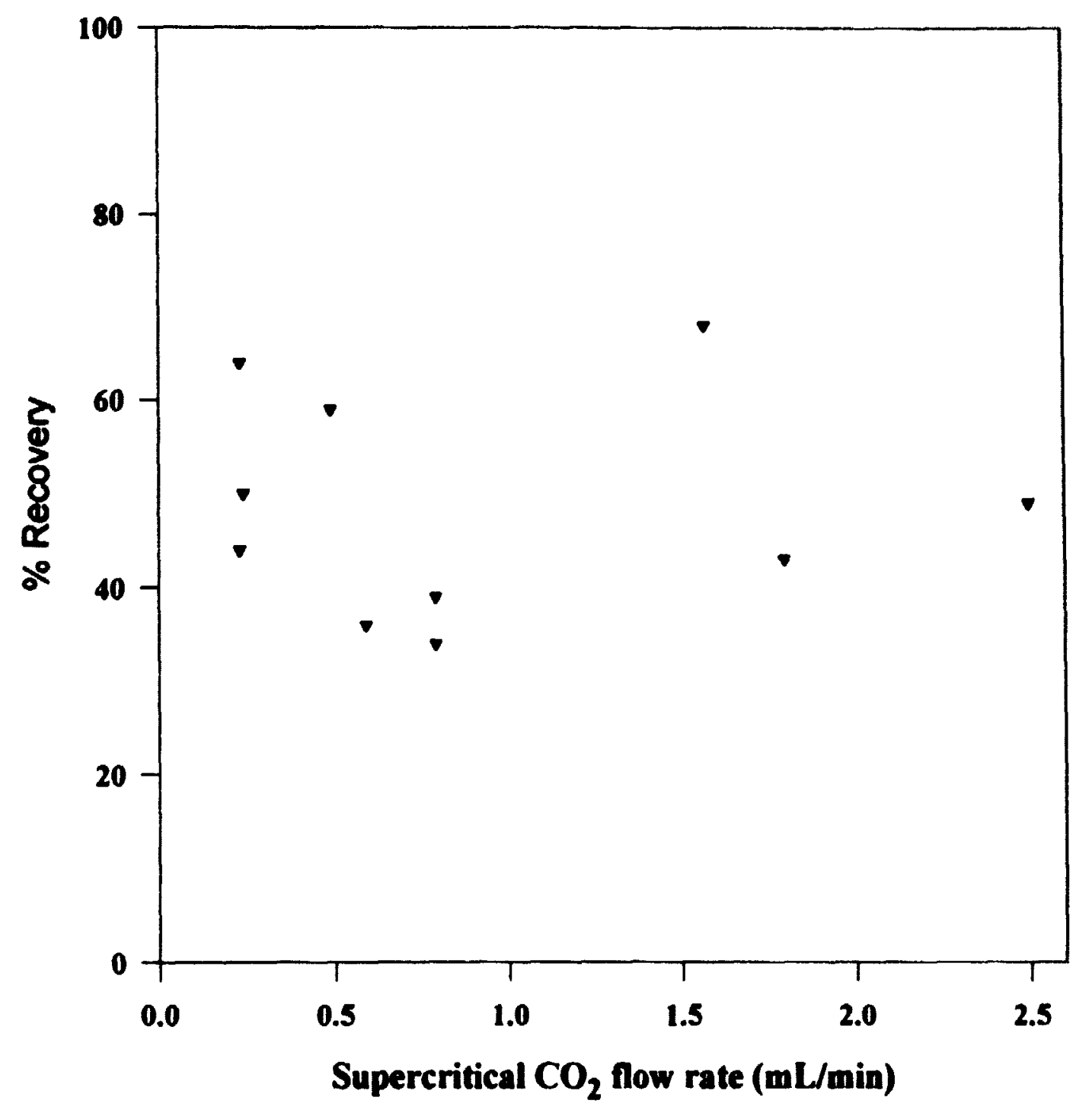

Figure 4.1 $\mathrm{PCP}$ recovery, extraction condition: $3000 \mathrm{psi}, 40^{\circ} \mathrm{C}, \mathrm{SFCO}$ density 0.85 $\mathrm{g} / \mathrm{mL}, 20 \mathrm{~mL} \mathrm{SFCO}$ 
The rate of the rise of a drubble is determined by the radius and the density of the $\mathrm{SFCO}_{2}$ drubble. Neither of these two factors should change dramatically with flow rate. At high flow rates there will simply be a greater rate of formation of drubbles. The amount of PCP transferred from water to the drubbles will be the same per drubble; i.e. per total $\mathrm{SFCO}_{2}$ volume. The radius of the drubble may be somewhat greater at higher flow rates as the pressure difference across the holes in the drubbles would be greater. However, there would be expected to be better mass transfer at higher flow rates as there would be more turbulence, i.e. better mixing, when more drubbles are moving in the water at the same time.

Faster flow rates are desirable as they allow for faster extractions; a greater volume of fluid can be put through the extraction vessel in a given time. However, high flow rates can lead to problems in trapping.

Summarizing, the disadvantages of the system are:

(1) the restrictor plugged easily,

(2) the flow rate was irreproducible,

(3) the trap was too long, so that difficulties were encountered when rinsing the trap, and (4) the total time spent including the extraction and washing of the trap was more than 2 hours.

On the other hand, the main advantage of this restrictor is that the pressure drops at one point (at the end of the tube). Consequently the expansion does not take place along the tube as in fused silica capillary restrictors (Mellor et al. 1994). 
There the pressure drops down the length of the silica restrictor (see section 2.2.2.3). As the density decreases and solute or water can precipitate out on the inside of the capillary.

\subsubsection{SFE using a fused silica capillary as restrictor.}

The aforementioned drawbacks motivated attempts to develop a system able to cut down the number of steps, and thus the time of the extraction procedure. Instead of using the $1 / 16$ "tube crimped at the end, fused silica capillary tubing was used (Polymicro Technologies, internal diameter $49-48 \mu \mathrm{m}$, coating 14-15). The same restrictor was described by Burk (1990). The flow rate is controlled by the length and the internal diameter of the capillary; the longer and narrower, the slower the flow. The length of the restrictor used was $30 \mathrm{~cm}$, achieving a flow rate of $1.3 \mathrm{~mL} / \mathrm{min}$ of $\mathrm{SFCO}_{2}\left(\right.$ at $40{ }^{\circ} \mathrm{C}$ and $3000 \mathrm{psi}$ ). The restrictor was heated in order to avoid breakage (see section 3.3.2).

Problems were anticipated with the use of a capillary restrictor because of the water content of the $\mathrm{SFCO}_{2}$ (see section 2.3.1). The silica becomes fragile when it adsorbs water. This problem did not materialize. However, in anticipation of it, some runs were done with a tube of dried sodium sulfate set before the restrictor (after valve 2) in order to remove the water. There seemed to be no problem in having a drying tube in the system, but it was subsequently not used as the expected problems with water content did not materialize. The flow rate remained constant throughout the extraction and as many as 20 extractions could be performed with the same capillary. 
The capillary permitted the collection of the extract directly in a solvent. For this purpose the ideal tube should be large and thin so that small amount of solvent would be required. Several tubes were tested: Taperlok ${ }^{\text {TM }}$ Sample tube, scintillation vials (as described by ONeill, 1994), reactivial (as described by Burk, 1990), centrifuge tubes, and vial screw top gl $16 \mathrm{~mL}$.

With the Taperlok ${ }^{M}$ Sample tube, only $0.5 \mathrm{~mL}$ of methanol was required, but most of it was flushed out due to the violence of the depressurization. The same happened with the reactivial and scintillation vials. The centrifuges tubes were found to be ideal for the trapping. In this study, a rubber septum was put over the tube, but as a result contamination problems were met which interfered in the HPLC analysis. Having a teflon cap which completely sealed the system would make an excellent option. It was, however, not possible to verify this in the study.

Finally the vial screw top $g l 16 \mathrm{~mL}$ with a teflon cap was used. Among all the tested traps, this proved to be the most suitabie. Collection of the analyte into a liquid solvent may cause loss of analyte due to aerosol formation. A second trap was therefore set up a second trap (Figure 3.2b). However, analysis of the second trap provided no evidence of PCP.

The results obtained with this trap were compared with those obtained with the solid trap and the one reported in the literature. The trapping system provided a significant improvement over collection of analyte into a solid trap. The time of extraction is cut by $20 \mathrm{~min}$. 
Table 4.1 PCP recoveries by two different restrictors and traps.

\begin{tabular}{|c|c|c|c|}
\hline Tral & \# estractions & " PC P recovered & "aRSU \\
\hline solid phase & & & \\
\hline vial $(16 \mathrm{~mL})$ & 10 & 49 & 24 \\
\hline literature & 3 & 48 & 20 \\
\hline
\end{tabular}

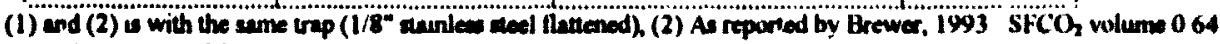
tuma the volume of the sample

\subsection{Effect of temperature on SFE}

The solvent strength of a supercritical fluid is dependent on its density. By varying the pressure or temperature the density varies; it increases as the temperature decreases at constant pressure. Experiments were performed at room temperature $\left(21^{\circ} \mathrm{C}\right)$, where the density of the fluid at $3000 \mathrm{psi}$ is $0.94 \mathrm{~g} / \mathrm{mL}$. It is then not necessary to wait for the system to reach thermal equilibrium; this saves $20 \mathrm{~min}$ in the extraction time.

For the initial feasibility studies, $20 \mathrm{~mL}$ of $\mathrm{SFCO}_{2}$ were used. The mean of three extractions was $56(\%$ RSD of 3$)$ compared with those obtained at $40{ }^{\circ} \mathrm{C}$ of $48 \%$ (\%RSD of 20). Subsequent extractions were therefore performed at room temperature, except those described below:

After exhaustive extraction $\left(40 \mathrm{~mL}\right.$ of $\left.\mathrm{SFCO}_{2}\right)$ (see section 4.4.3), the recoveries of PCP attained at $21{ }^{\circ} \mathrm{C}$, pressure of 3000 psi were of the order of $60 \%(\% R S D=13)$ (Table 4.3). Recoveries of the order of $90 \%$ were reported by Brewer (1994), with extractions at $40^{\circ} \mathrm{C}$, pressure of $3000 \mathrm{psi}, \mathrm{SFCO}_{2}$ density of $0.85 \mathrm{~g} / \mathrm{mL}$, flow rate of 08 
$\mathrm{mL} / \mathrm{min}$. However, it is important to note that the results were obtained with a different extraction vessel. Visual observations of gas bubbling through the drubbler in water show that the formation of bubble field is very sensitive to the quality of the holes drilled into the drubbler.

Exhaustive extraction at $40^{\circ} \mathrm{C}$ were repeated, to see if higher temperature increased PCP recovery. The results are summarized in table 4.2. The mean after five extractions was $67 \%$ ( $\%$ RSD of 19) (Table 4.2$)$ as compared to $60 \%(\%$ RSD of 13$)$ at $21^{\circ} \mathrm{C}$ (Table 4.3).

Increases in temperature lead to decreases in the $\mathrm{SFCO}_{2}$ density, reducing its solvent strength (as discussed in section 2.1.1). It is thus expected to obtain lower value of $K$ and less analyte would be recovery. The vapour pressure of the solute is however increased, increasing solubility in the SF (see section 2.1.2). Some authors have suggested that an increase in the temperature increases the extraction efficiency of polar compounds (Daneshfar et al., 1995) since the water content in the $\mathrm{SFCO}_{2}$ rich phase increases; the water thus modifies the polarity of $\mathrm{SFCO}_{2}$. On the other hand, at higher temperatures, the solubility of the analyte in the water rich phase should increase The experimental results indicate that a change of temperature from $21^{\circ} \mathrm{C}$ to $40^{\circ} \mathrm{C}$ does not affect the extraction efficiency. 
Table 4.2 Extractions efficiencies at $40^{\circ} \mathrm{C}$ with the fused silica capillary and $40 \mathrm{~mL}$ of $\mathrm{SFCO}_{2}$ passed through the sample

\begin{tabular}{|l|c|}
\hline $\begin{array}{c}\text { Flow } \\
(\mathrm{mL} / \mathrm{min})\end{array}$ & \% Recovery \\
\hline 1.10 & 57 \\
\hline 1.10 & 57 \\
\hline 1.10 & 89 \\
\hline 0.75 & 62 \\
\hline 0.52 & 70 \\
\hline Mean & 67 \\
\hline \%RSD & $19 \%$ \\
\hline
\end{tabular}

\subsection{Effect of fulvic acid on the extractions}

It was hypothesized that the current extraction techniques may be able to extract free analytes, but not those bu - dissolved organic matter (DOM) if the interactions between the analytes and DOM are sirong. The amount of such analytes present in the sample could, therefore, be underestimated.

As discussed in section 1.2, DOM in natural water is composed mainly of humic substances (HS) in concentrations up to 25 to $100 \mathrm{mg} / \mathrm{L}$ (Maguire et al., 1995).

Recognizing the importance of DOM in the behaviour of organic compounds, fulvic acids were selected to represent DOM in natural water. Pentachlorophenol was chosen as a representative compound of the chlorophenol class.

Pentachlorophenol (PCP) is considered as a polar compound due to its acidic properties (pK. of 4.35). The $K_{\text {ow }}$ values reported are 3.69 (Geyer et al. 1994) and 5.01 (Veith et al., 1979), suggesting intermediate lipophilicity. It was expected that, on one 
hand, interaction between $P^{P} C P$ and FA should be present. On the other hand, extractions of PCP by $\mathrm{SF} \mathrm{CO}_{2}$ should be quantitative (see section 2.1.2).

\subsubsection{Liquid Liquid Extraction (LLE)}

Because LLE does not require special equipment and is easy to perform, LLE is a widely used technique.

As mentioned in section 3.4, PCP can be analyzed by method 515.5 (US EPA), by which PCP is extracted with ethyl ether. Since dichloromethane (DCM) is a more suitable solvent for this, the EDA method was modified to use DCM.

Incompatibility between DCM and the HPLC mobile phase (methanol) was observed; quantification of PCP in DCM was thus complicated. As a result, after the extraction, DCM was evaporated and the sample reconstituted with methanol. Controls for each set of extraction were performed: a certain amount of PCP from the PCP stock solution was spiked in a preweighed vial containing DCM which was treated in the same manner as the samples. No significant losses due to evaporation were found. Extraction recoveries of PCP from $20 \mathrm{~mL}$ samples ( $[P C P]=0.200 \mathrm{mg} / \mathrm{L}$ ) ranged from 72 to $92 \%$.

The presence of FA in solution at a concentration of about $20 \mathrm{mg} / \mathrm{L}$ showed no significant effect on the extraction efficiency of PCP (Table 4.3). Thus DCM can easily compete with FA for the PCP.

\subsubsection{Solid Phase Extraction (SPE)}

The method approved by the US EPA is 515.2, by which a Poly(Styrenedivinylbenzene) SDB disk is used. The eluting solvent is $10 \%$ of methyl-t-butyl ether in 
methanol (MTBE/MeOH). Recovery of PCP by this method has been reported to be 69 (\%RSD of 11) (Cram et al., 1996). In this study, dichloromethane (DCM) proved to be a good eluting solvent, giving a recovery of 69 (\%RSD of 10) (Table 4.3). Two transfer steps are involved in SPE; PCP from water to the solid phase and PCP from the solid phase to the DCM.

Even though the amount of solvent used in SPE is less than in LLE, toxic solvents are still required. Moreover, the problem of the disposal of the solid phase has been neglected. Recoveries are also highly dependent on the analyst skills.

Table 4.3 PCP recovery with three different methods; the samples were extracted on the loth day after their preparation $([P C P]=0.200 \mathrm{mg} / L)$.

\begin{tabular}{|c|c|c|c|}
\hline & \multicolumn{3}{|c|}{ Extraction Method } \\
\hline & LLE & SPE & SFE \\
\hline $\begin{array}{c}\text { PCP in water } \\
\text { Mean } \\
\% \text { RSD } \\
\# \text { cases }\end{array}$ & $\begin{array}{l}86 \\
9 \\
5 \\
\end{array}$ & $\begin{array}{l}69 \\
10 \\
5\end{array}$ & $\begin{array}{l}60 \\
13 \\
4 \\
\end{array}$ \\
\hline $\begin{array}{r}\text { PCP in FA } \\
\text { Mean } \\
\% \text { RSD } \\
\text { \#cases }\end{array}$ & $\begin{array}{l}83 \\
12 \\
6\end{array}$ & $\begin{array}{l}71 \\
6 \\
3\end{array}$ & $\begin{array}{l}46 \\
9 \\
5\end{array}$ \\
\hline
\end{tabular}

PCP/W PCP epiked in deionized waler (final concentration of 0.200 ppm) PCP/FA PCP spiked in $20 \mathrm{mg}$ FAL rolution (0 $200 \mathrm{me} / \mathrm{L}$ PCP LLE: liquid-liquid extraction with dichloromethane

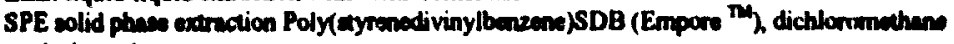
as eluting solven:

SFE Supercritical fluid extraction, trapping in $\mathrm{MCOH}$ 


\subsubsection{Supercritical fluid extraction (SFE)}

\section{Extraction profiles}

In order to get the extraction profiles for PCP, a number of vials were used. For example, in the course of a single extraction, the vial was replaced after each $20 \mathrm{~mL}$ of $\mathrm{SFCO}_{2}$ giving three extracts. Figure 4.2 is a representation of the profiles for the two kinds of samples. The results suggest that the presence of FA makes the extraction of PCP less effective. 


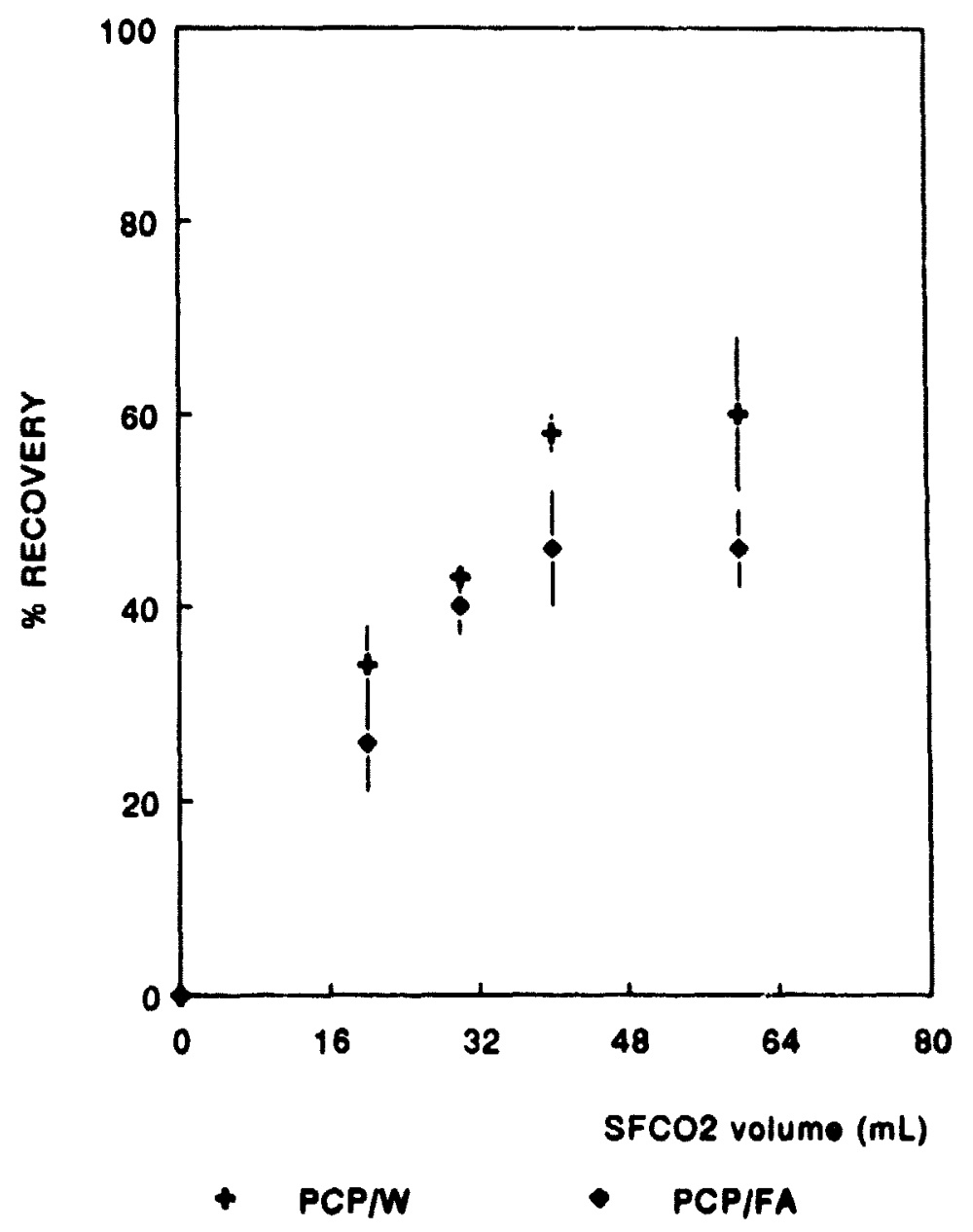

Figure 4.2 Extractions profiles of pentachlorophenol at $21^{\circ} \mathrm{C}$ a) without fulvic acid and b) with fulvic acid. Minimum of three experiments per point, the data can be found in Table III.2 (Appendix 3). 
Efrect of fulvic acids in the extraction efficiency

The results shown in table 4.3 indicates that the percent of recovery obtained by LLE and SPE was not affected by the presence of fulvic acids at $20 \mathrm{mg} / \mathrm{L}$ (Figure 4.3). This suggests the presence of weak interactions between PCP and fulvic acids. This interactions can be overcome by the DCM used in LLE and the styrenedivinylbenzene groups in the Empore ${ }^{\text {TM }}$ disk; however, the interactions might not be fully overcome by the carbon dioxide $\left(\mathrm{CO}_{2}\right)$ in SFE. With $\mathrm{SFCO}_{2}$ the recovery was reduced from $60 \%$ (with FA) to $46 \%$ (with FA), based on non overlap of one standard deviation (Figure 4.2 at 60 $\mathrm{mL}$ of $\mathrm{SFCO}_{2}$ and Figure 4.3).

A further statistical analysis (ANOVA), showed no statistically significant differences in the extraction efficiency in the presence of FA for SFE when 0.05 was chosen as the level of significance (Appendix 4, Table IV.4). Although goodness of fit validated the model, it seem that the level of significance chosen may be excessively strict considering the relative standard deviation of the results (Table 4.3).

The weak interactions between FA and PCP can be explained as suggested in the literature (Stevenson, 1994). For acid/basic compounds, two kinds of interactions could be found. Ion exchange is unlikely to be an important mechanism for humic substances when the compound is an acid, but hydrophobic bonding could occur, as it increases as the solute becomes more nonpolar. Active surfaces for hydrophobic bonding include aliphatic side chains on humic and fulvic acids (Figure 1.1, page 5). 
It is believed that the way by which the sample is prepared might have some effect on the interactions. In this study the sample was unbuffered, and made from deionized water which has a pH about $5.6( \pm 0.2)$. It is known that fulvic acids act as a buffer in natural water. The $\mathrm{pH}$ of the solution after adding the FA was in the order of $5.2( \pm 0.2)$. No significant change was observed after adding the PCP (final concentration of PCP of $0.200 \mathrm{mg} / \mathrm{L}$ ). At pH 5.2, $12.5 \%$ of the initial PCP is in the protonated form; presumably hydrogen bond interactions are not present.

\section{Comparison between extraction methods}

In order to compare the performance of each extraction, one kind of sample will be selected (PCP/FA). The highest recovery was obtained by LLE followed by SPE and finally SFE. However, based on one standard deviation, the difference between LLE and SPE is not statistically significant, in contrast with the differences between LLE and SFE (Figure 4.3).

Reports indicate that at the SFE experimental conditions $\left(3000\right.$ psi and $\left.21^{\circ} \mathrm{C}\right)$, the $\mathrm{pH}$ of the solution is about 2.85-2.9 (Table 2.1). The partitioning of the PCP to the $\mathrm{SFCO}_{2}$ is favored by this $\mathrm{pH}$ lowering, as $96.5 \%$ of the PCP are in the protonated, more hydrophobic for.n. On the other hand, the lower, the pH the more protonation of the FA sites. The $\mathrm{pH}$ is lowered to 2 with the addition of $\mathrm{H}_{2} \mathrm{SO}$, prior the LLE and SPE.

However, SFE experiments with such low pH values were not attempted. 


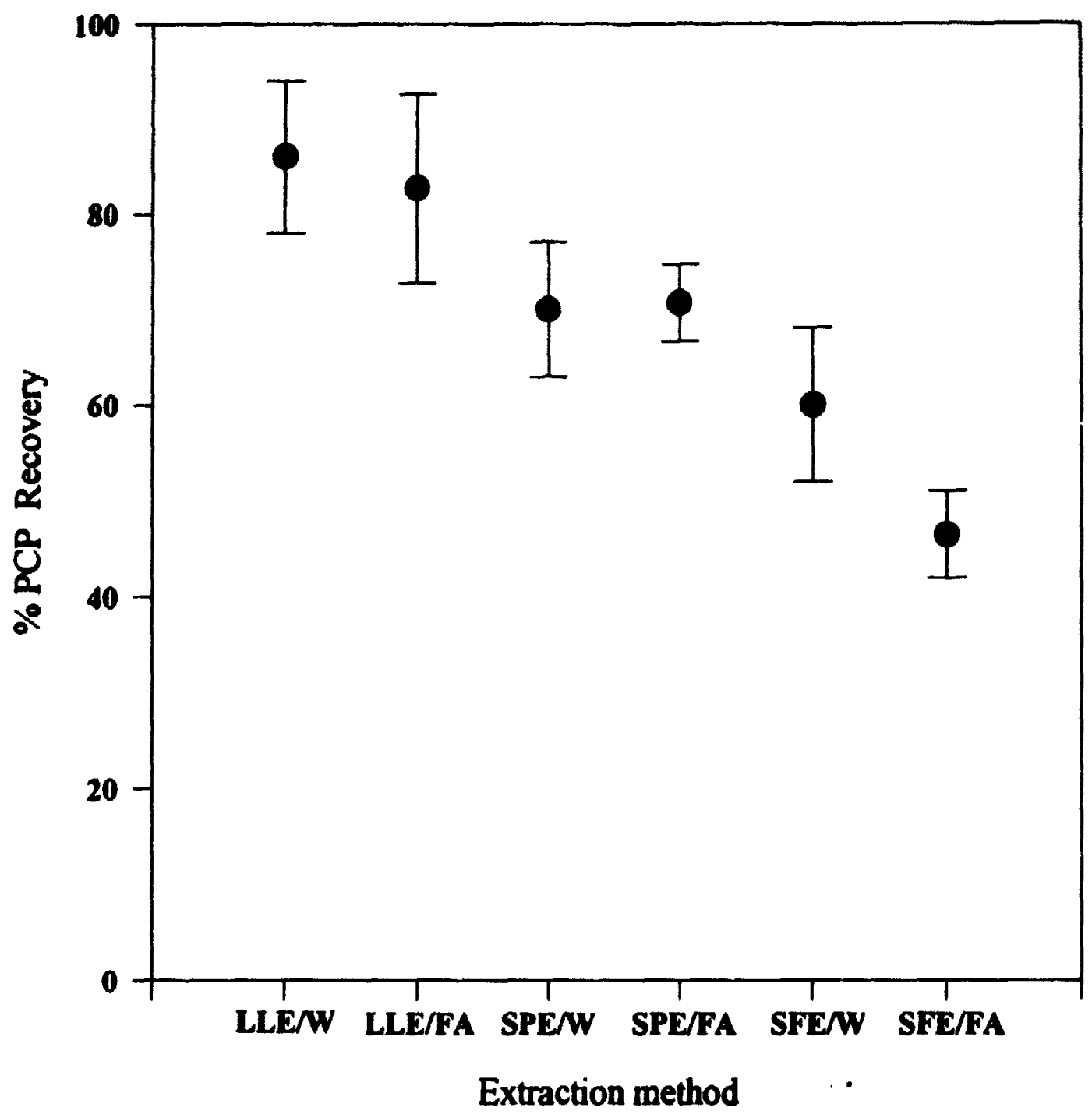

Figure 4.3 PCP recoveries obtained by different methods in absence and presence of fulvic acids; the average and error bars ( \pm I sid) are plotted for each extraction method. 


\subsection{Pentachlorophenol extractions from Ottawa river water}

Most of the results reported in the literature described extractions from spiked reagent water (see section 2.2), which differs considerably from natural river water. The results, therefore, do not reflect what actually happens in real samples since there is no consideration of interactions between organic compounds and suspended solids, and organic compounds and DOM.

Pentachlorophenol was spiked into the Ottawa river water, and it was extracted by LLE, SPE and SFE as described in section 3.5 .

Results of the water quality of the Ottawa river were provided by the Britannia Purification Plant. Of all the organic compounds listed in the drinking water surveillance progra a, 2,4,6-trichlorophenol was detected in concentrations of the order of $0.05 \mathrm{ppb}$ (Table 1.2, page 7). The average amount of dissolved organic carbon and dissolved solids are 6.4 and $37.2 \mathrm{ppm}$ respectively (Table 1.1, page 7).

The results are in accordance with those obtained with the fulvic acid solution: the extraction efficiencies ranked as LLE $>$ SPE $>$ SFE. In spite of the emulsion formed in LLE, the recoveries were higher but the time needed for the phases to separate was longer than for previous LLEs. 
Table 4.4 PCP recovery with three different methods: LLE, SPE and SFE. Volume of sample: $20 \mathrm{~mL}$ and concentration of PCP $200 \mathrm{ppb}$.

\begin{tabular}{|c|c|c|c|}
\hline & \multicolumn{3}{|c|}{ EXTRACTION METHOD } \\
\hline & LLE & SPE & SFE \\
\hline Mean & $87 \%$ & $63 \%$ & $55 \%$ \\
\hline$\%$ RSD & $5 \%$ & $10 \%$ & $11 \%$ \\
\hline \# cases & 5 & 6 & 5 \\
\hline
\end{tabular}

ULE: tiquid-liquid extrection with dichloromethene

SPE solid phere extraction Poly(nyrendivinylbenzene)SDB (Empore TM)

dichicromahue as eluting solver

SFE Supercritical Ruid extraction, trepping in MoOH 
Chapter 5 


\section{CONCLUSIONS}

The use of supercritical fluid $\mathrm{CO}_{2}$ for the extraction of pentachlorophenol from water samples was investigated, and compared to liquid liquid and solid phase extraction.

\subsection{Feasibility studies}

In the first part of the project some feasibility experiments were performed in order to cut down the time in the extraction process. The modification made to the system and to the extraction condition are summarized as follows:

\subsubsection{Apparatus.}

Collection of the extract was achieved by using a fused silica capillary instead of 1/16 " stainless steel tube crimped at the end. As a result, extractions were performed at constant flow rate (at equal $T$ and $p$ ). The fused silica restrictor allowed the collection of the extract directly into $2 \mathrm{~mL}$ of methanol.

\subsubsection{Extraction}

Extractions of PCP were performed at room temperature $\left(21^{\circ} \mathrm{C}\right.$ at $\left.3000 \mathrm{psi}\right)$.

The differences in the percent of recovery at this condition $\left(\mathrm{SFCO}_{2}\right.$ density $0.94 \mathrm{~g} / \mathrm{mL}$ ) compared with those obtained at $40{ }^{\circ} \mathrm{C}\left(\mathrm{SFCO}_{2}\right.$ density $\left.0.85 \mathrm{~g} / \mathrm{mL}\right)$ were not significant. This decreased the time of an extraction by $20 \mathrm{~min}$. 


\subsection{Effect of fulvic acid in the extraction of PCP by LLE, SPE and SFE}

The presence of fulvic acids (FA), at a concentration of $20 \mathrm{mg} / \mathrm{L}$, do not interfere in the extractions efficiency by LLE and SPE. Graphical results showing one standard deviation (Figure 4.3) suggest that the presence of FA lowers the recovery of PCP with SFE. With FA, the recovery is $46 \%$ vs $60 \%$ without FA. However, at the level of significance chosen in advance $(0.05)$ the hypothesis was rejected. It seems that this level is to strict considering the relative standard deviation of the results. It can be concluded that FA do not interfere with the extraction of PCP by LLE, SPE. This suggests only a weak interaction between FA and PCP.

In comparing the percent of recovery obtained by each method it can be seen that there are differences between extractions; LLE gave the highest recovery.

\subsection{Application of SFE to real samples}

Extractions of PCP from real samples showed the same trend (percent of recovery is higher by LLE > SPE $>$ SFE. There are differences between methods, with LLE giving the highest recovery. 
The following table is a summary of the three methods used in this study. The comparison is done in terms of precision and performance.

Table 5.1 Comparison of extraction methods for PCP.

\begin{tabular}{|l|l|l|l|l|l|l|}
\hline $\begin{array}{c}\text { Extraction } \\
\text { method }\end{array}$ & $\begin{array}{c}\text { Detec } \\
\text { Limit }\end{array}$ & $\begin{array}{c}\text { Precision } \\
\% \text { RSD }\end{array}$ & Expense & Time & $\begin{array}{c}\text { Solvent } \\
\text { use }\end{array}$ & $\begin{array}{c}\text { Easy to } \\
\text { perform }\end{array}$ \\
\hline LLE $^{(1)}$ & ppb & 9 & Low & 2 hours & $6 \mathrm{~mL}$ & Yes \\
\hline SPE & ppb & 10 & Medium & 1 hour & $6 \mathrm{~mL}^{(2)}$ & Yes \\
\hline SFE & ppb & 13 & Medium & 1 hour & $2 \mathrm{~mL}$ & Yes \\
\hline
\end{tabular}

The results obtained in this work show disadvantages and some advantages in the use of supercritical fluid extraction for analytical purpose. It may be possible tc overcome the disadvantages, as relatively little research has been done in optimizing direct SFE from water. The advantages of the reduction of solvent and of time may make SFE as suitable as SPE for standard usage.

On a longer scale, SFE could also be successfully used in water treatment.

There is definitely more to be done in this field of research. 
Chapter 6 


\section{REFERENCES}

Akgerman, A., Carter, D. B., J. Chem Eng. Data, 1994, 39: 510-512

Arcand, Y., Hawari, J., Guiot, S.R., Wat. Res. 1995, 29(1): 131-136

Barnabas, I.J., Dean, J.R., Hitchen, S.M, Owen, S.P., J. Chromatogr., 1994, A 665: 307315

Brewer, S.E., Kruus, P. J. Envirom Sci. Health, 1993, B28(6): 671-685

Brewer, S.E., Kruus, P, Burk, P. Proceedings of the 3rd international symposium on supercritical fluids, 1994, 2: 269-274.

Bruno, T.J.; Ely, J.F. Supercritical Fluid Technology: Reviews in modern Theory and Applications, CRC Press London, 1991, 405-449

Burk, R.C. Supercritical Fluid Extraction of Trace organics from Sılid Matrices, 1990. PhD Thesis, Carleton University

Canadian Water Quality Guidelines, 1987 Canadian Council of Resource and Environment Minister, revised in 1992.

Chang, Ch., Huang, I. Separation Science and Technology, 1995, 30(5), 683-695

Cram, S.P., Hawthorne, S.B., Markell, C. New Environmental Sample preparation rechniques, ACS Short Courses, Americal Chemical Society, 1996

Daneshfar, A., Barzegar, M., Ashraf-Khorassani, M. J. High Resol. Chromatogr., 1995, 18: 446-448.

Daniel, W.W., Biostatistics: A foundation for analysis in the health sciences, 1991.

John Wile \& Sons, Inc. Fifth edition, pp 740

Environmental Protection Agency 500 series methods: Methods for the determination of organic compounds in finished drinking water 1988. U.S. Department of commerce. National techical information service.

Geyer, H., Politzki, G., Freitag, D., Chemosphere, 1984, 13: 269

Ghonasgi, D., Gupta, S., Dooley, K M., Knopf, F.C. The Journa! of Supercritical Fluids, 1991a, 4, 53-59 
Ghohasgi, D, Gupta, S., Dooley, K.M., Knupf, AIChE Jowrnal, 1991b, 3(6), 944-950

Grasselli, J.G., Atlas of Spectral data and physical constants for organic compounds. CRC Press.

Hayes, M.B, MacCarthy, P., Malcolm, R.L., Swift, R.S., Humic substances II, In search of structure, 1989, John Wiley \& Sons,

Hedrick J.L, Taylor, L.T. Journal of High Resolution Chromatography, 1990, 13: 132 136

Hendrick, J.L, Mulcahey, L.J., Taylor, I.T. in ACS symposium series Supercritical Fluid Technology. Theoretical and Applied Approaches to Analytical Chemistry. 1992a, ACS. 206-220.

Hedrick J.L, Taylor, L.T. Journal of High Resolution Chromatography, 1992b, 15 , 151-154

Janda, V., Bartle, K. D, Clifford, A. Journal of Chromatography, 1993, 642: 283-299

Jiménez, B., Moltó J.C., Font, G. Chromatographia, 1995, 4I(5/6): 318-324

Jorens, P.G., Schepens, P.J., Human \& Experimental Toxicology, 1993, 12: 479-495

Kile D, E, Chiuo, C. T. in:

Suffet. I. H., MacCarthy, P. Aquatic Humic Substances, Influence on Fate Treatment of Pollutants, 1989, American Chemical Society, Washington.

King, M.B., Mubarak, A., Kim, J.D., Bott, T. K. The Journal of Supercritical Fluids, 1992, 5: 296-302.

Koester, C.J. and Clement, R.E. Critical Reviews in Analytical Chemistry, 1993. 24(4):263-316

Liu, Y., Lopez-Avila, V., Alcaraz, M., Anal. Chem. 1994, 66: 4483-4489

Macnaughton, S.J., Foster, N.R., Ind Eng. Chem. Res, 1994, 33: 2757-2763

Maguire, R.J., Batchelor, S.P , Sullivan, C.A. Environmental Toxicology and Chemistry, 1995, I4(3):389-393

Majors, R.E., LC-GC, 1995, 10(12): 912-916.

Mellor, F., Just, U., Strumpf, Th. Journul of Chromatography A, $1994679:$ 147-152 
Moors, M., Massart, D.L., McDowal, R.D., Pure \& Appl Chem, 1994, 66(2):277-304

O'Neill, M.L., The effects of supercritical Fluids on Amorphous Polymers. 1994, Ph.D. Thesis, Carleton University.

Prausnitz, J. M., Lichtenthaler, R.N., Gomes de Azevedo, E. Molecular Thermadynamics of fluid-phase equilibria, 1986, 2nd edition. pp600

Roop, R. K., Akgerman, A. J. Chem. Eng. Data, 1990, 35:257-260

Schafer K, Brauman, W. Fresenius'Z. Anal Chem, 1989332 pp 884

Sengupta, S., Gupta, S., Dooley, M., Knopf, F.C., The Journal of Supercritical Fluids, 1994, 7:201-209

Shimoda, M., Ishikawa, H., Kawano, T., Osajima, Y. Journal of Food Science, 1994, $59(1), 231-233$

Starostin, L, Witkievicz, Z., Chem Anal (Warsaw), 1994 39: 63-279

Stevenson, F.J. Humus chemistry: genesis, composition, reactions, 1994, 2nd ed. John Wiley \& Sons, Inc.

Suffet, 1.H., MacCarthy, P., Aquatic Humic Substancec. Influence on Fate and Treatment of Pollutants, 1989, American Chemical Society, Washington.

Toews, K.L, Shroll, R.M, Wai, C., Anal Chem 1995, 67: 4040-4043

Thorton J.D., Science and Practice of Liquid-Liquid Extraction, 1992, Oxford University Press, pp603

Varian. LC Star Workstation, operator's Manual, 1990, Varian Associates, Inc. page 14-62-63.

Veith, G.D., Austin, N.M., Morris, R.T. Water Res., 1979, 13:43

Wang, J., Marshall, W.D., Gamble, D.S., Analyst, 1996, 121: 1-7

Wiebe, T., Gaddy, V. L., Am. Chem. Soc., 1941, 63, 475

Yeo, S-D., Akgerman, A, AIChE Journal, 1990, 36(11): 1743-1747 
Appendix 

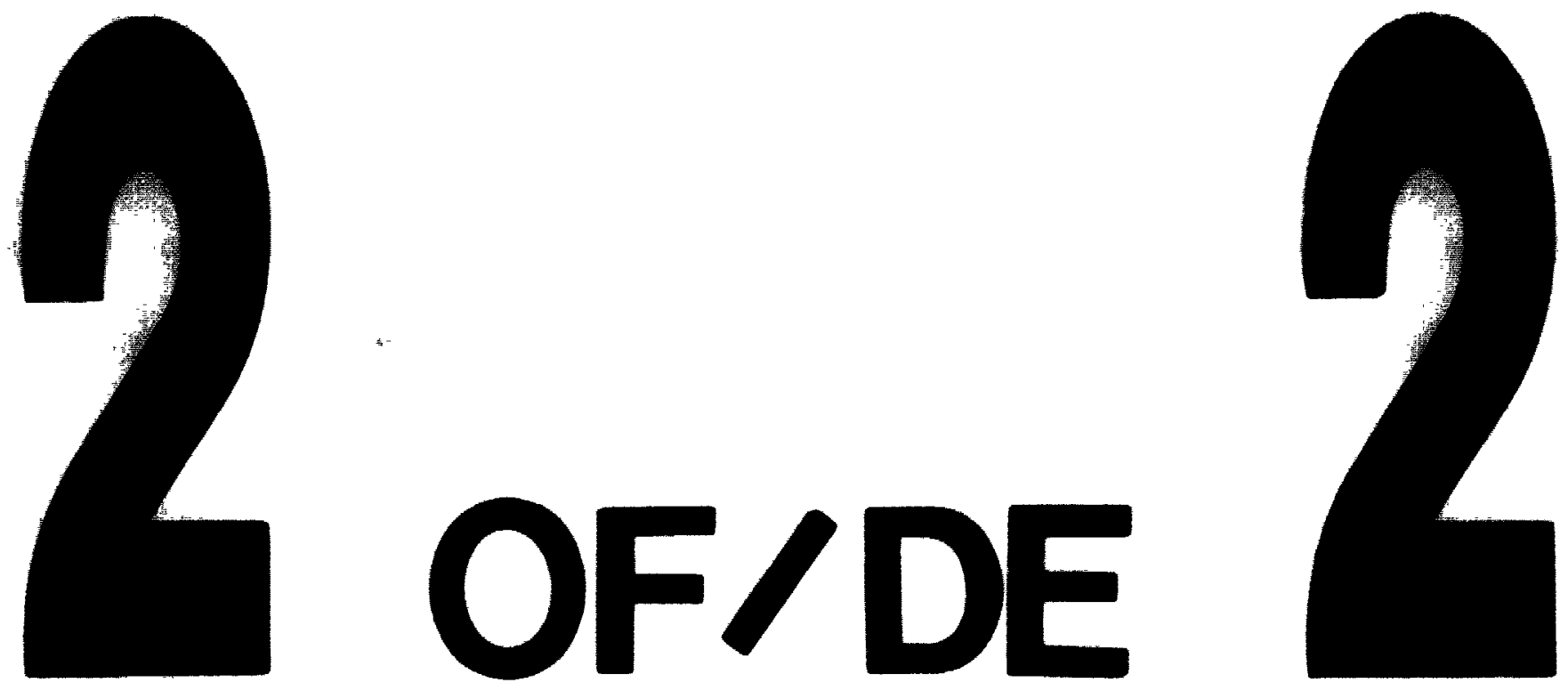

PM $13^{\circ}:$ : 4 PHOTOGRAPHIC MACROCOPY TARGET NBS 1010 aNSI/1SO $=2$ EOUIVALENT

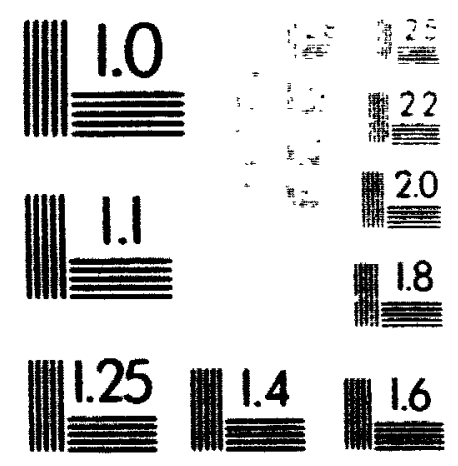

PAECISLONsm RESOLUTION TARCETS 


\section{APPENDIX 1: PCP Chromatograms}

Mobile phase $95 \% \mathrm{MeOH}$ and 5\% (0 5\% Acetic acid) Flow rate $15 \mathrm{~mL}$ min. wavelength $224 \mathrm{~nm}$.

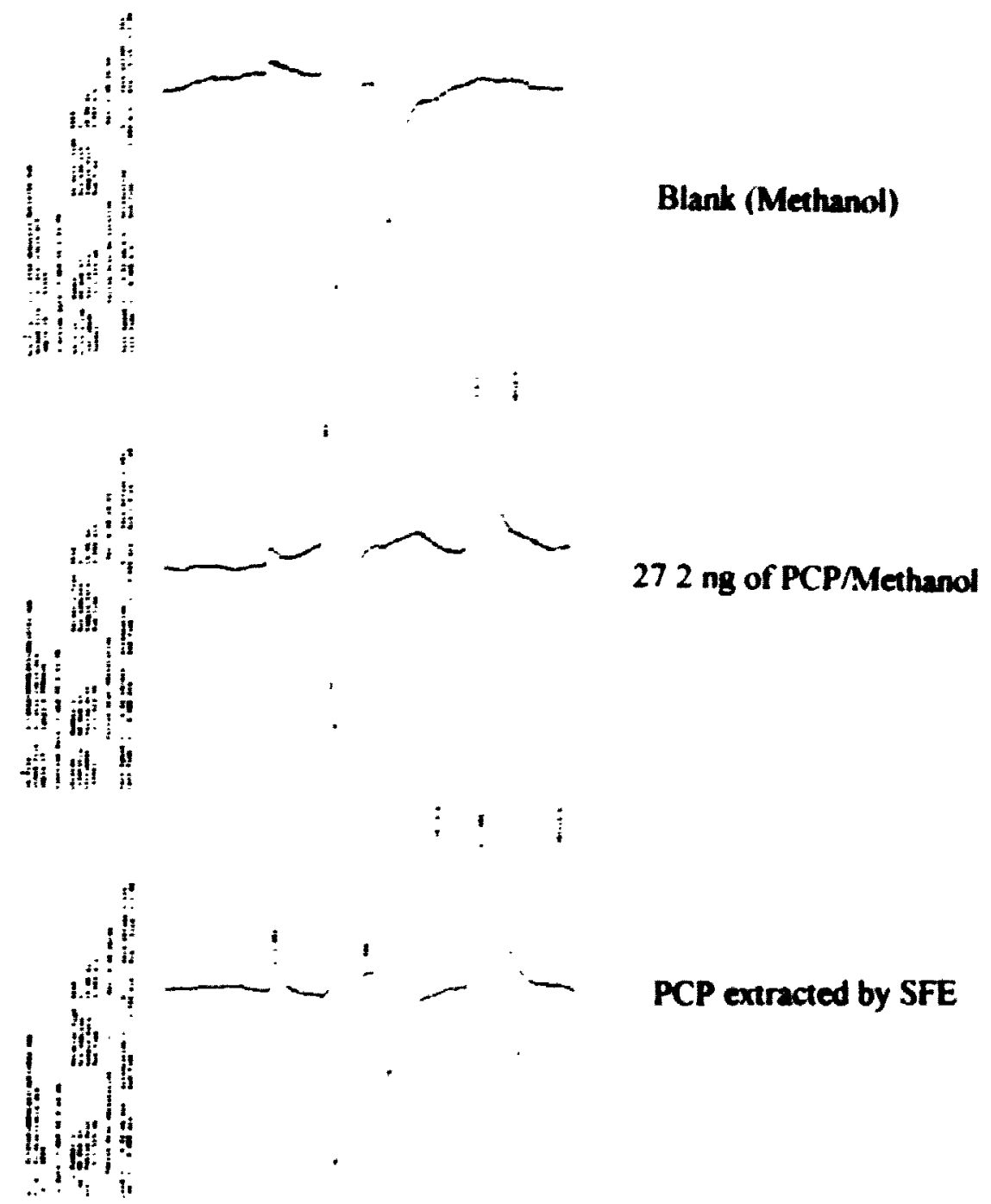




\section{APPENDIX 2: PCP Calibration curve}

The volume injected was $30 \mu \mathrm{L}$ of standard in methanol.

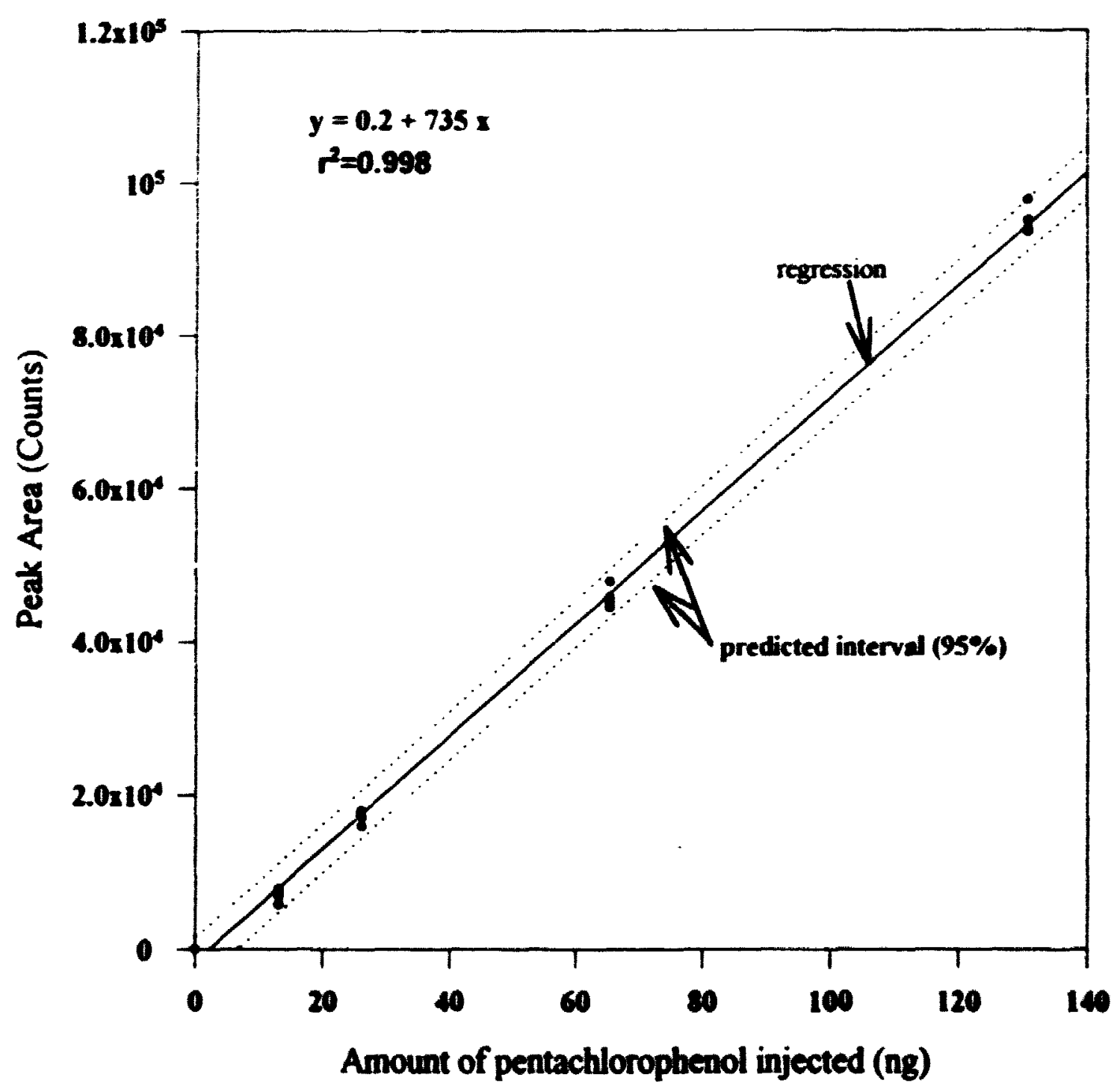




\section{APPENDIX 3: PCP recoveries as function of volume of $\mathrm{SFCO}_{2}$}

Table III.1 PCP recovery as function of volume of SF(\%): passed through the sample (cumulative). The samples were extracted afier one dan of sample preparation.

\begin{tabular}{|c|c|c|}
\hline & volum & $2(\mathrm{~mL})$ \\
\hline \multirow[t]{2}{*}{ Sample } & \multicolumn{2}{|c|}{$\%$ Recovery } \\
\hline & $20 \overline{\mathrm{mL}}$ & $60 \mathrm{~mL}$ \\
\hline \multirow[t]{4}{*}{$\mathrm{PCP} / \mathrm{W}$} & 45 & 66 \\
\hline & 30 & 59 \\
\hline & 39 & 63 \\
\hline & 36 & 61 \\
\hline $\begin{array}{l}\text { Mean } \\
\text { std } \\
\text { RSD }\end{array}$ & $\begin{array}{c}38 \\
6 \\
16\end{array}$ & $\begin{array}{c}62 \\
3 \\
5\end{array}$ \\
\hline \multirow{3}{*}{ PCP/FA } & 25 & 66 \\
\hline & 29 & 65 \\
\hline & 31 & 55 \\
\hline Mean & 28 & 62 \\
\hline sed & 3 & 6 \\
\hline RSD & 10 & 10 \\
\hline
\end{tabular}


Table III.2 $P(P$ recovery as function of $S F$ volume. The samples were extracted ten days after sample preparation. Data plotted in figure 4.2.

\begin{tabular}{|c|c|c|c|c|}
\hline & \multicolumn{4}{|c|}{ Volume of $\mathrm{SFCO}_{2}(\mathrm{~mL})$} \\
\hline \multirow[t]{2}{*}{ Sample } & \multicolumn{4}{|c|}{$\%$ Recovery } \\
\hline & $20 \mathrm{~mL}$ & $30 \mathrm{~mL}$ & $40 \mathrm{mi}$ & $60 \mathrm{~mL}$ \\
\hline PCP/W & 31 & 43 & 56 & \\
\hline & 39 & & 58 & 67 \\
\hline & 35 & & & 50 \\
\hline & 31 & & & 57 \\
\hline & & & & 66 \\
\hline Mean & 34 & 43 & 57 & 60 \\
\hline $\begin{array}{c}\text { atd } \\
\% \text { RSD } \\
\end{array}$ & $\begin{array}{r}4 \\
11 \\
\end{array}$ & & & $\begin{array}{c}8 \\
13\end{array}$ \\
\hline & 28 & 43 & 43 & \\
\hline PCP/FA & 28 & 42 & 48 & \\
\hline & 35 & 39 & 47 & 53 \\
\hline & 27 & 37 & 55 & \\
\hline & 29 & & & 43 \\
\hline & 23 & & 38 & 49 \\
\hline & 22 & & & 45 \\
\hline & 18 & & & 42 \\
\hline Mean & 26 & 40 & 46 & 46 \\
\hline and & 5 & 3 & 6 & 4 \\
\hline KRSD & 19 & 8 & 13 & 9 \\
\hline
\end{tabular}




\section{APPENDIX 4: Statistical analysis}

Table IV.I PCP recoveries as function of flow rate. Extructoms performed a 3000 psi and $10{ }^{\circ} \mathrm{C}: S F \mathrm{CO}_{2}$ densin: $0.85 \mathrm{~g} \mathrm{mL:} \mathrm{SF}$ volume: $20 \mathrm{~mL}$ : sold phase trup. Data plotted in figure $4 . I$

\begin{tabular}{|c|c|c|}
\hline Group & Flow $\mathrm{mL} / \mathrm{min}$ & $\%$ Recovery \\
\hline \multirow{3}{*}{1} & 024 & 59 \\
\hline & 023 & 44 \\
\hline & 0.23 & 64 \\
\hline \multirow[t]{3}{*}{2} & 049 & 59 \\
\hline & 0.59 & 36 \\
\hline & 0.78 & 39 \\
\hline \multirow[t]{3}{*}{3} & 160 & 68 \\
\hline & 1.80 & 43 \\
\hline & 2.0 & 49 \\
\hline & & \\
\hline
\end{tabular}

Hypothesis

Ho: The flow rate has no influence in the recoveries. The recoveries are the same. Ha: At least one is different.

Table IV.2 Analysis of variance at 0.05 level of significance ( $\alpha$ )

\begin{tabular}{llllll}
\multicolumn{1}{c}{ Source } & $\begin{array}{r}\text { Sum of } \\
\text { squares }\end{array}$ & $\begin{array}{c}\text { Degrees of } \\
\text { freedom }\end{array}$ & $\begin{array}{r}\text { Mean } \\
\text { square }\end{array}$ & F-ratio & P value \\
Group & 291.067 & 2 & 145.533 & 1.073 & 0.392 \\
Error & 949.333 & 7 & 135.619 & 135.619 &
\end{tabular}

The null hypothesis is not rejected, therefore, the flow rate does not have influence in the recoveries. 
Table IV.3 (omparison betu een extraction methods (LLE. SPE and SFE) for PCP in deionized water and PCP in a solution containing 20 ppm of FA. Data are summarizing in table 4.4.

\begin{tabular}{|c|c|c|c|c|c|c|}
\hline \multicolumn{7}{|c|}{$\%$ RECOVERIES } \\
\hline & \multicolumn{2}{|c|}{$\begin{array}{c}\text { Liquid Liquid } \\
\text { Extraction (LLE) }\end{array}$} & \multicolumn{2}{|c|}{$\begin{array}{c}\text { Solid Phase } \\
\text { extraction (SPE) }\end{array}$} & \multicolumn{2}{|c|}{$\begin{array}{l}\text { Supercritical Fluid } \\
\text { Extraction (SFE) }\end{array}$} \\
\hline & 1 week & 2 weeks & I week & 2 weeks & I week & 2 weeks \\
\hline \multirow[t]{6}{*}{ PCP/W } & 93 & 98 & 70 & 74 & 66 & 67 \\
\hline & 70 & 78 & & 77 & 59 & 66 \\
\hline & 80 & 90 & & 61 & 63 & 50 \\
\hline & & 82 & & 68 & 61 & 57 \\
\hline & & 82 & & & & \\
\hline & & & & & & \\
\hline Mene & 81 & 86 & 70 & 69 & 62 & 6013 \\
\hline \multirow[t]{4}{*}{ RSD } & 14 & 9 & & 9 & 5 & 13 \\
\hline & & & & & & \\
\hline & & & & & & \\
\hline & 70 & 92 & & 75 & & 53 \\
\hline \multirow[t]{5}{*}{ PCP/FA } & 79 & $9 i$ & & 67 & & 49 \\
\hline & 85 & 73 & & 70 & & 43 \\
\hline & 91 & 92 & & & & 45 \\
\hline & 76 & 76 & & & & 42 \\
\hline & & 72 & & & & \\
\hline & & & & & & \\
\hline Meas & 80 & 83 & & 71 & & 46 \\
\hline RSD & 10 & 12 & & 6 & & 9 \\
\hline & & & & & & \\
\hline
\end{tabular}

LIE Didharamedne

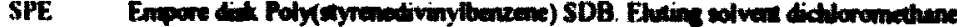

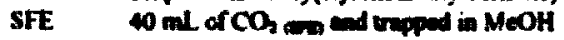


In the two factorial expermiental design. the hypotheses are

1) Interactions between method and sample (sampie*method) It is of interest to see if the combinations of sample and method give different results In other words, if the extraction efficiency varies with sample arid method Therefore, the hypotheses are

Ho there is no differences

Ha At least one is different

2) If the extraction efficiency is affected by the kind of sample (sample)

Ho The presence or absence of FA does not affect in the extraction efficiency

Ha: There is differences

3) Finally, if the extraction efficiencics are different depending on the kind of extraction (method)

Ho The extraction efficiencies are the same for all the methods

Ha: At least, one is different.

Decision rule: Reject Ho if $\mathrm{p}$ value is higher than 0.05 (level of confidence)

Table IV.4 ANOVA, differences between extraction method and sample type

\begin{tabular}{|c|c|c|c|c|c|}
\hline Source & $\begin{array}{l}\text { Sum of } \\
\text { squares }\end{array}$ & $\begin{array}{l}\text { Degrees of } \\
\text { freedom }\end{array}$ & $\begin{array}{l}\text { Mean } \\
\text { square }\end{array}$ & F-ratio & P value \\
\hline Sample & 189.003 & 1 & :39.003 & 3277 & 0085 \\
\hline Method & 4747.447 & 2 & 2373.759 & 41.157 & 0.000 \\
\hline $\begin{array}{l}\text { Sample* } \\
\text { method. }\end{array}$ & 223.447 & 2 & 111.724 & 1937 & 0169 \\
\hline Error & 1211200 & 21 & 57676 & & \\
\hline
\end{tabular}


According to the AN(JVA, the first and second null hypotheses are not rejected The conclusions with a 005 of level of confidence

1) Extraction efficiencies are not influence by the presence of fulvic acids

2) At least one method differs in the recoveries 
APPENDIX 5: Pressure conversion table

$$
\begin{aligned}
1 \mathrm{~atm} & =101325 \times 10^{5} \mathrm{~N} \mathrm{~m}^{-2} \text { (or Pa) } \\
& =101325 \mathrm{bar} \\
& =760 \mathrm{Tor} \\
& =101325 \mathrm{kPa} \\
& =1470 \mathrm{psi}
\end{aligned}
$$




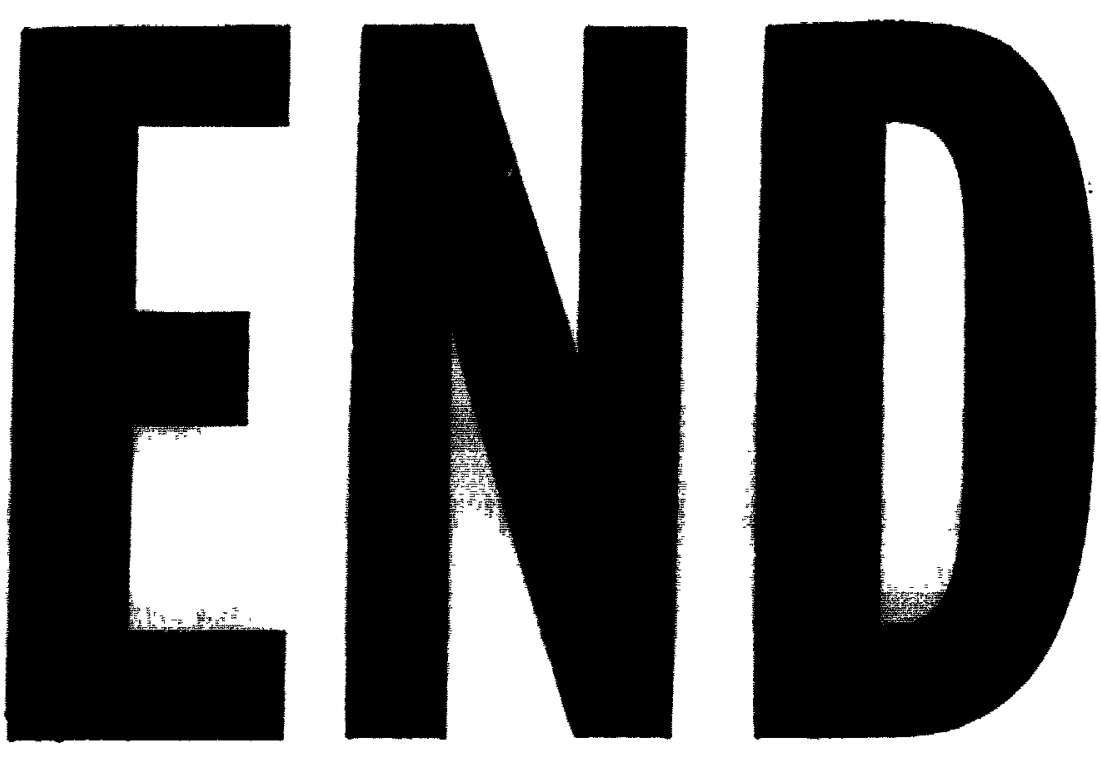

19.06 .97
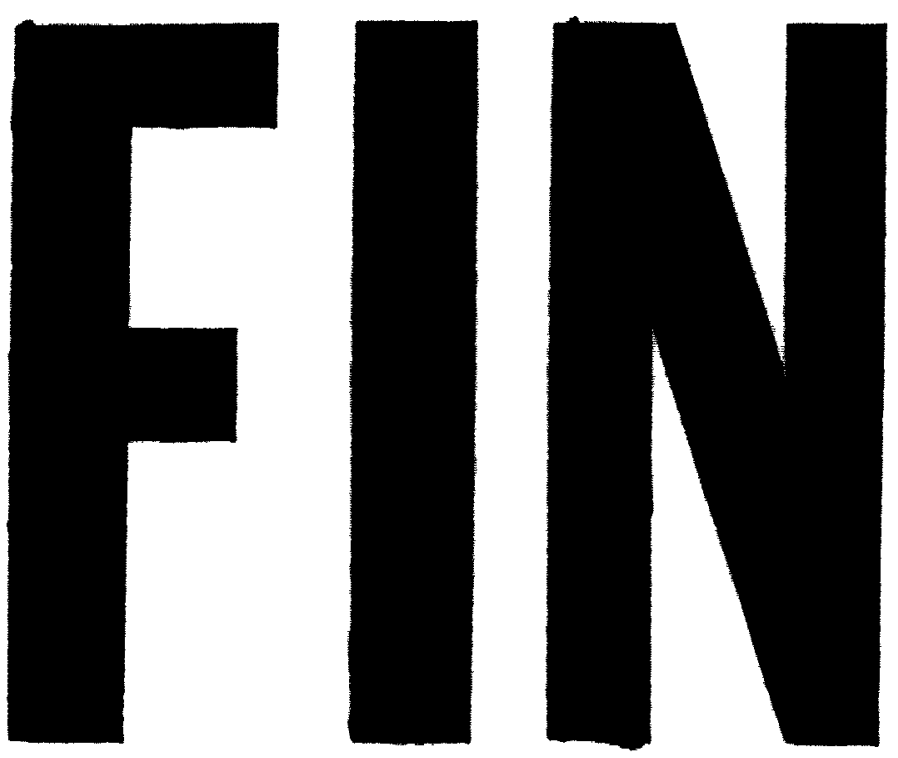